\title{
Bioaccumulation in Milford Haven Waterway
}

\author{
W J Langston ${ }^{\mathrm{a}^{*}}$, N D Pope ${ }^{\mathrm{a}}$, S O’Hara ${ }^{\mathrm{a}}, \mathrm{M} \mathrm{Imamura}^{\mathrm{a}}, \mathrm{H}$ Harino $^{\mathrm{b}}, \mathrm{Kim}, \mathrm{A} . \mathrm{W}^{\mathrm{c}}$. and \\ C H Vane \\ ${ }^{\mathrm{a}}$ Marine Biological Association, Citadel Hill, Plymouth PL1 2PB \\ ${ }^{\mathrm{b}}$ School of Human Sciences, Kobe College, 4-1 Okadayama, Nishinomiya, Hyogo 662-8505, Japan \\ ${ }^{c}$ British Geological Survey, Kingsley Dunham Centre, Keyworth, NG12 5GG
}

Keywords: Milford Haven, bioaccumulation, metals, PAHs, PCBs, organotins

\begin{abstract}
Biomonitoring of contaminants (metals, organotins, PAHs, PCBs) was carried out along the Milford Haven Waterway (MHW) and at a reference site in the Tywi Estuary during 2007-2008. The species used as bioindicators encompass a variety of uptake routes - Fucus vesiculosus (dissolved contaminants); Littorina littorea (grazer); Mytilus edulis and Cerastoderma edule (suspension feeders); and Nereis diversicolor (omnivore which often reflects contaminants in sediment). Differences in feeding strategy and habitat preference have subtle implications for bioaccumulation trends though, with few exceptions, contaminant body burdens in Milford Haven $(\mathrm{MH})$ were higher than those at the Tywi reference site, reflecting inputs.
\end{abstract}

Elevated concentrations of metals were occasionally observed at individual $\mathrm{MH}$ sites, whilst As and Se (molluscs and seaweed) were, for much of MHW, consistently at the higher end of the UK range. However, for the majority of metals, distributions in $\mathrm{MH}$ biota were not exceptional by UK standards. Several metal-species combinations indicated increases in bioavailability at upstream sites, which may reflect the influence of geogenic or other land-based sources - perhaps enhanced by lower salinity (greater proportions of more bioavailable forms).

TBT levels in MH mussels were below OSPAR toxicity thresholds and in the Tywi were close to zero. Phenyltins were not accumulated appreciably in Mytilus, whereas some Nereis populations may have been subjected to localized (historical) sources.

PAHs in Nereis tended to be evenly distributed across most sites, but with somewhat higher values at Dale for acenaphthene, fluoranthene, pyrene, benzo(a)anthracene and chrysene; naphthalenes tended to be enriched further upstream in the mid-upper Haven (a pattern seen in mussels for most PAHs). Whilst concentrations in $\mathrm{MH}$ mussels were mostly above reference site and OSPAR backgrounds, it is unlikely that ecotoxicological guidelines would be exceeded.

PCBs in mussels were between upper and lower OSPAR guidelines and were unusual in their distribution in that highest levels occurred at the mouth of $\mathrm{MH}$.

Condition indices (CI) of bivalves (mussels and cockles) were highest at the Tywi reference site and at the seaward end of $\mathrm{MH}$, decreasing upstream along the Waterway. There were a number of significant (negative) relationships between CI and body burdens and multivariate analysis indicated that a combination of contaminants could influence the pattern in condition (and sub-lethal responses such as MT and TOSC) across sites. Cause and effect needs to be tested more rigorously in future assessments.

\footnotetext{
${ }^{*}$ Corresponding author: wjl@mba.ac.uk
} 


\section{Introduction}

The Milford Haven Waterway is a ria-type estuary, unique in Wales, forming part of the Pembrokeshire Marine Special Area of Conservation (Burton, 2006). The Haven is fully marine for some $12 \mathrm{~km}$ from the mouth (to the confluence of the Pennar River) with a shoreline of $>100 \mathrm{~km}$. The Daucleddau -the common Estuary of E\&W Cleddau Rivers (Figure 1) - is also marine (mesohaline) for much of its length because of the small ingress of FW relative to the tidal incursion (Nelson-Smith, 1965).

Despite its important conservation status, the Waterway is subjected to contaminants from several sources including E \& W Cleddau Rivers, industry (e.g. oil refineries), waste water discharge (WWTW), diffuse inputs associated with landfill leachate, urban development, agricultural run-off and atmospheric deposition. Maritime operations and pollution incidents (hydrocarbons and antifouling), dredging and spoil disposal add to this inventory (Atkins, 2005). The harbour was host to $>50 \mathrm{M}$ gross tonnes shipping in 2009, supplying, among other cargoes, $25-30 \%$ of the UK's petrol, diesel and, recently, liquefied natural gas. Contamination by biologically-deleterious substances has implications for the 'favourable condition status' of the site and other conservation objectives. Potential impact on fauna, at its most extreme, was highlighted by the 'Sea Empress' oil spill in 1996.

Milford Haven has been a major oil terminal since the 1960s and has received chronic releases of hydrocarbons ( $<250$ tonnes pa, overall) by a variety of routes including refineries, power stations, shipping, road run-off and small-scale domestic sources. These inputs are dispersed along the waterway in association with suspended particulates (Little et al., 1987; Nikitik and Robinson, 2003). The loss of $>70000$ tonnes of light crude oil and 480 tonnes of heavy fuel oil from the Sea Empress in 1996 represented a significant departure from this trend (though $<15000$ t are estimated to have reached the shoreline, and only a fraction of this entered the Haven, 
with very little reaching the Cleddau Estuaries). Nevertheless, hydrocarbon residues were dispersed along considerable stretches of the MH waterway, with heaviest contamination of sediments reported in the lower reaches (Nikitik and Robinson, 2003). Prior to this (and subsequently) hydrocarbon levels in fine sediments generally displayed a gradient decreasing from the upper estuary, seaward, and were more indicative of pyrogenic and degraded chronic input than crude oil. The higher values upstream are presumed to reflect the up-estuary transport of fines in this flood-tide dominated system.

Sediment PAH 'hotspots' $>100,000 \mu \mathrm{g} \mathrm{kg}^{-1}$ at MH, reported by Woodhead et al., (1999), were above the Threshold for Effects Level (TEL) for $\sum$ PAHs of $1684 \mu \mathrm{g} \mathrm{kg}^{-1}$ (dry weight), and also above the Probable Effects Level (PEL) of $16770 \mu \mathrm{g} \mathrm{kg}^{-1}$ (dw) implying ecotoxicological significance. However up until the time of the accident there was little monitoring of biological-effects baselines, particularly sub-lethal 'markers' which may be most relevant in quantifying the 'health' status of populations.

Reports of oil-related biological impacts from the Sea Empress imply varying degrees of deleterious effects, though in most cases recovery appears to have been complete within five years. Shellfish including limpets (Patella spp), winkles (Littorina spp), razor shells (Ensis ensis), trough shells (Mactra corallina) and cockles Cerastoderma edule were subjected to mass mortalities in oiled areas though mussels Mytilus edulis were relatively tolerant to oiling and were only acutely affected in areas sprayed with detergent. C. edule populations were the only commercial shellfish to suffer major mortalities but recovery appears to have been rapid, albeit fluctuating in scale (Rostron 1998). Our own observations in 2007/8 indicate fairly abundant populations of mussels and cockles (and other bioindicator species) at each of the selected sites in MH waterway, upstream as far as Black Tar (figure 1). A subsequent survey in 2010 
has shown that distributions of M.edulis and C.edule extend even further upstream - to the confluence of E. and W. Cleddau. Subjective indications are that cockles may be less common than in 2008, however, coinciding with reduced numbers described elsewhere in the region, particularly the Loughor Estuary, S Wales.

Following the spill, biomarkers of genotoxicity revealed responses in some fish species - though not in mussels (Law et al., 1998; Harvey et al., 1999). Immunosuppression in mussels was, however, severe immediately after the accident, but recovery followed a few months later (Dyrynda et al., 2000). Reduction of phagocytosis and intra-cellular superoxide production (both defence mechanisms for killing infectious agents) were correlated with mussel body burdens of oil-derived and, in particular, combustion-derived PAHs; extra-cellular superoxide production was more strongly related to oil-derived PAHs.

Reduced scope for growth (SFG)- a physiological stress response in mussels - was recorded in samples from Milford Haven in 1996 and 1997, much of which was thought attributable to PAHs and, to a lesser extent, organotins, though the authors suggest that other 'unknown' compounds may have also contributed to effects (Widdows et al., 2002). Of all Irish Sea sites sampled, the concentrations of 2- and 3ring PAHs were highest in mussels from $\mathrm{MH}$, sampled 6 months after the Sea Empress oil spill (>20000 $\left.\mu \mathrm{g} \mathrm{kg}^{-1} \mathrm{dw}\right)$. By the following year (1997) concentrations had declined by $\sim 66 \%$, reflecting recovery after the oil-spill, but were still relatively high (4000 to $7800 \mu \mathrm{g} \mathrm{kg}^{-1}$ dry wt.) - more than an order of magnitude above those in the current survey.

Bioassays using sediments from some sites in MHW induced a reduction in feeding activity in lugworm Arenicola marina though acutely toxic effects were not demonstrated in these assays (Law et al., 1998). At the community level, there were reduced numbers of sensitive amphipods following the spill, accompanied by 
increases in opportunist polychaetes (e.g. Capitella) in the Middle and Lower Haven. Diversity has recovered to varying degrees in different parts of the Waterway by 2000, even though abundances were generally still low (Nikitik and Robinson, 2003).

The importance of $\mathrm{MH}$ port is likely to increase in coming years, and will see a rise in contaminant-related pressures: hence the value of establishing a monitoring programme - to ensure unacceptable deterioration does not occur as a result of anthropogenic events. Bioaccumulation surveillance will help statutory agencies (Milford Haven Port Authority, Countryside Council for Wales, the Environment Agency), and industry, in their environmental protection responsibilities.

Biomonitoring is valuable addition to the tools available to assess the adverse effects of contamination (water quality analysis, toxicity testing and ecological survey) because it provides a direct measure of the bioavailability of contaminants. Bioaccumulation is not only an important component of environmental quality assessment but also, for commercial species, can have implications for human health. Shellfish gathering in MHW is currently mainly small-scale - for mussels, winkles, cockles, clams, oysters and razor fish. Limited seaweed harvesting occurs, primarily for the making of laver bread.

It may seem most relevant to base the choice of biomonitoring organism on one or more species consumed by humans. However, there are other considerations which stem from the fact that different contaminants have their own characteristics and that organisms accumulate them from a variety of sources, often at different rates, adopting diverse accumulation strategies. Consequently, there is no universal indicator organism and the most useful monitoring programmes are likely to include analyses of several species, preferably of differing ecological types (primary producer, detritivore, herbivore, filter feeder). Selection of indicators should be appropriate to the chemistry and form (dissolved, particulate, dietary) of the 
contaminants of concern. Hence, by integrating results for several different species a broad appraisal of impact is obtained. The selection of species in the current project represents an appropriate blend i.e. Fucus vesiculosus (dissolved contaminants); Littorina littorea (grazer); Mytilus edulis and Cerastoderma edule (suspension feeders that accumulate from both dissolved phase and suspended particulates); and Nereis diversicolor (an omnivore which often strongly reflects bioavailable contaminants in sediment e.g. Bryan et al, 1985; Langston and Spence, 1995).

By combining the information gained from these species a reasonable picture of the significance of biologically-available contaminants in MHW will be achieved. A similar rationale was adopted for earlier EA (NRA) bioaccumulation surveys in Wales (Davies and Ellery, 1995), which, though limited, represent the only long-term bioaccumulation data for the Haven. Continuation of this strategy, based on similar species and sites, provides an opportunity to establish whether there has been improvement or deterioration in contamination levels, as well as providing a contemporary baseline against which future change can be gauged.

In the context of detecting environmental change, and to make data comparable with earlier surveys, we have made efforts to minimize the effects of biotic factors such as seasonality and size (Bryan et al., 1985; Langston and Spence, 1995). For metals and some organotins, MBA has data for the same species for most estuaries in Wales and England. Harmonised sampling routines have thus helped to facilitate nationwide comparisons and to achieve other key objectives of the current study, namely to establish a rigorous bioaccumulation programme that offers wide coverage within MHW; to undertake bioaccumulation surveillance on a range of metals and organic contaminants; and to assess current status and to provide benchmarks for future comparisons, making use of earlier surveys where possible. 


\section{Materials and methods}

\subsection{Sampling}

Field-survey work in Milford Haven was undertaken on two occasions: September 2007 (N. diversicolor and L. littorea) and March 2008 (M. edulis, C. edule and F. vesiculosus). Reference samples for each species were also collected in the Tywi Estuary at these times. Sites are shown in Figure 1; grid references and species occurrences are summarised in Table 1.

Because of different habitat preferences, sites for sediment dwellers (N.diversicolor, C.edule) and rocky shore species (L.littorea, M. edulis and F. Vesiculosus) were not always identical but were as close as practical.

All biota were returned live to the laboratory and immediately submitted to clean-up procedures (Bryan et al., 1985) in preparation for freeze-drying and analysis. Whole organism size, weight and tissue wet and dry weight data were recorded. Condition indices (CI) for bivalves describe the relationship between soft tissue dry weight and the organism total size. High CI values are considered an integrated signal of better 'health' status. The condition index used in this study was $\mathrm{CI}_{4}$ as defined in Lundebye et al., 1997:

$\mathrm{CI}=($ Soft tissue dry weight $(\mathrm{g}) \times 1000) /(\text { shell length }(\mathrm{cm}))^{3}$

\subsection{Analysis}

Contaminant analyses were performed on batches of 60 pooled mussels and cockles, 30-100 winkles, 250-600 Nereis and 20 Fucus plants, freeze-dried to constant weight and homogenised to a fine powder. Metals were analysed in all species; several classes of organic contaminants (organotins, PAHs, PCBs) were also analysed in $M$. edulis and $N$. diversicolor. 


\section{Metals}

Metals analysed included: Ag, As, Cd, Co, Cr, Cu, Fe, $\mathrm{Hg}, \mathrm{Mn}, \mathrm{Ni}, \mathrm{Pb}, \mathrm{Se}, \mathrm{Sn}$, and Zn. Sub-samples $(0.5 \mathrm{~g})$ of freeze-dried homogenate were digested with $5 \mathrm{ml} \mathrm{HNO}_{3}$ (Fisons Primar grade) and $1 \mathrm{ml} \mathrm{H}_{2} \mathrm{O}_{2}$ in a Milestone (1200 Mega) microwave digestion system. For analysis of Ag, a hotplate digestion of a separate subsample was employed (Langston et al., 1994a). Digests were analysed by Flame Atomic Absorption, or, where concentrations were low, by Graphite Furnace AA. Hg and Se were analysed by cold vapour and hydride generation systems, respectively. To prepare samples for arsenic and total tin analysis, $5 \mathrm{ml}$ ashing slurry $(6 \%$ magnesium nitrate, $10 \%$ magnesium oxide) were added to sub- samples of the freeze-dried homogenate; these were ashed in a muffle furnace and dissolved in $10 \mathrm{ml} \mathrm{HCl}$ prior to analysis by hydride generation AA. Quality assurance included the use of the Certified Reference Materials DORM-2 (National Research Council), LUTS-1 and IAEA-140 (seaweed), ensuring that determinations fell within the confidence intervals of the assigned values. Detection limits for metals ranged from $0.01(\mathrm{Sn})$ to 0.1 $(\mathrm{Cu}, \mathrm{Zn}) \mu \mathrm{g} \mathrm{g}^{-1} \mathrm{dw}$

Biometric and contaminant data were input to Microsoft Excel spreadsheets. Statistical analyses were performed using Statistica (Statsoft Corp.). Metals data were interlinked to the larger MBA database (Langston et al 1994b). In order to place MH results into context, $\mathrm{MH}$ data are ranked in comparison to the rest of the UK and expressed as percentiles of the values present in the database. Summary plots for all species and maps for M.edulis are shown here. Maps for other species are provided as electronic supplementary material (Figs A-D). MH data below the lower quartile value (lowest $25 \%$ of UK values) are plotted as green bars, red if above the upper quartile (highest $25 \%)$. Values in the mid range $\left(25-75^{\text {th }}\right.$ percentile) are plotted as grey bars. 


\section{Organotins}

Compounds analysed included: monobutyl-, dibutyl- and tributyltin (MBT,DBT, TBT) and monophenyl-, diphenyl- and triphenyltin (MPT, DPT,TPT) based on methodology of Harino et al. (2005). Tissue samples, including aliquots spiked with standards, were extracted with $\mathrm{HCl}$ and acetone, followed by tropolone-benzene, then propylated and cleaned on florisil, prior to analysis by GC-FPD. The detection limits were $\sim 0.004 \mu \mathrm{g} \mathrm{g}^{-1}$ dry wt. Quality assurance was established using certified reference materials, PACS-1, CRM 462,477.

\section{Polyaromatic hydrocarbons (PAHs)}

Seventeen PAHs were assayed in M.edulis and N. diversicolor, ranging from 2 ring naphthalene and 1-methyl-naphthalene (petrogenic), to six ring PAHs benzo[ghi]perylene and indeno[1,2,3-cd]pyrene, of probable pyrogenic origin (Law et al., 1999).

Freeze-dried tissue samples were extracted with acetonitrile and tetrahydrofuran (THF) aided by sonication. Clarified, filtered extracts were analysed by HPLC (gradient programming) equipped with scanning fluorescence detector (see Vane et al., 2007 for details). Quality control was achieved by subjecting a well-characterised, low-level PAH proficiency-testing marine sediment (Quasimeme - QPH048MS) to the above procedure. Three QCs and three procedural blanks were conducted at intervals throughout the analysis of the samples (duplicates). Limits of detection for PAHs ranged from 0.1 to $0.7 \mu \mathrm{g} \mathrm{kg}^{-1}$.

\section{Polychlorinated biphenyls (PCBs)}

The ICES 7 PCB congeners, 28, 52, 101, 118, 138, 153 and 180 were determined by gas chromatography mass spectrometry (GCMS) analysis. Freeze dried samples and CRMs were spiked with internal standards (PCBs: 019, 034, 062, 119, 147, 131, 173 
at $1.4-2.5 \mathrm{ng} / \mathrm{g}$ in hexane) The CRM was BCR-718 and the procedural blank was inert hydromatrix dispersant.

Samples were extracted by Dionex 200 accelerated solvent extraction (ASE) system. Stainless steel extraction cells $(33 \mathrm{ml})$ were filled with the sample, $2-3 \mathrm{~g}$ of copper powder and hydromatrix. Extraction conditions were: solvent acetone:hexane (1:1), temperature $100^{\circ} \mathrm{C}$, pressure 2000 psi, heat-up time $1 \mathrm{~min}$, static time 8 minutes, flush volume $120 \%$, purge time 60 seconds, total solvent used $37-44 \mathrm{~mL}$ per sample.

During clean-up, acetone was removed by mixing the extract with de-ionised water and disposing of the aqueous layer. The fatty-emulsion in the organic fraction was broken-down by the drop-wise addition of concentrated sulphuric acid $(10 \mathrm{~mL})$. The aqueous / organic phases were allowed to separate and the acidic layer removed. The organic phase was reduced to $8-10 \mathrm{~mL}$ and dried with anhydrous sodium sulphate. Interferences were removed using back-extraction with dimethylsulphoxide (DMSO). DMSO fractions were mixed with de-ionised water $(25 \mathrm{~mL})$ and extracted with $n$ hexane $(2 \times 50 \mathrm{~mL})$. The hexane extracts were combined, reduced to approximately $5 \mathrm{~mL}$ using rotary evaporation, and dried with anhydrous sodium sulphate. A recovery standard was added (containing PCB029 and PCB157, 0.40ng/g in hexane) and reduced to approximately $0.2 \mathrm{~mL}$ using nitrogen.

GCMS analysis was performed using Varian CP-3800 GC fitted with a Factor Four column (VF-1ms, $60 \mathrm{~m}, 0.32 \mathrm{~mm}, 0.25 \mu \mathrm{m})$. Oven temperature program was: $60^{\circ} \mathrm{C}(1$ minute isothermal) to $200^{\circ} \mathrm{C}$ (at $5^{\circ} \mathrm{C} / \mathrm{min}$ ) to $280^{\circ} \mathrm{C}$ (at $2.6^{\circ} \mathrm{C} / \mathrm{min}$ ) to $320^{\circ} \mathrm{C}$ (at $20^{\circ} \mathrm{C} / \mathrm{min}, 20$ minutes isothermal at $\left.320^{\circ} \mathrm{C}\right)$. Injection $\left(1 \mu \mathrm{L}, 250^{\circ} \mathrm{C}\right)$ was splitless for the first $0.7 \mathrm{~min}$ and 1:50 thereafter. Helium carrier gas was at $1 \mathrm{~mL} / \mathrm{min}$. Mass spectrometer (Varian 1200L) operating conditions were: selective ion monitoring $(\mathrm{m} / \mathrm{z}$ 57-328), $0.5 \mathrm{scans} / \mathrm{sec}$, ionization energy $70 \mathrm{eV}$, detector voltage fixed at 1700V. Data 
processing was performed using Varian MS Workstation (version 6.5). The limit of detection was $0.5 \mathrm{ng} / \mathrm{g}$.

Extensive contextual data are not available for organic contaminants and $\mathrm{MH}$ data have been compared with OSPAR Guideline values. For TBT and PCBs, OSPAR Environmental Assessment Criteria (EAC) in mussels have been used as generic benchmarks. The OSPAR scheme identifies two types of EAC: (1) "lower" concentrations, below which it is reasonable to expect that there will be an acceptable level of protection from chronic effects (presented as green bars in the maps for TBT and PCBs shown in the text and supplementary data); and (2) EAC "higher" concentrations above which it is reasonable to expect acute toxic effects on marine species (plotted as red bars). The concentrations in between these upper and lower values indicate sub-lethal effects cannot be ruled out (plotted in grey). Black bars are used where reference values have not been set for a particular contaminant.

The lower and higher OSPAR environmental assessment criteria (EAC) for TBT (mussels) are 0.012 and $0.175 \mathrm{mg} \mathrm{kg}^{-1}$ wet weight, respectively (OSPAR, 2004).

The lower and higher OSPAR environmental assessment criteria (EAC) for $\sum$ ICES7 chloro-biphenyls (CBs) in mussels are 0.75 and $7.5 \mu \mathrm{g} \mathrm{kg}^{-1}$ wet weight, respectively (OSPAR, 2000; NMMP 2004). These have been converted to dry weight value of 5 and $50 \mu \mathrm{g} \mathrm{kg}^{-1} \mathrm{dw}$ by multiplying by the average wet:dry weight ratio of 6.66 .

For a number of PAHs we have compared values in relation to OSPAR (2007) 'Background Concentrations' (BC-concentrations expected at undeveloped sites around the North Atlantic) and 'Background Assessment Criteria' (BAC) for mussels (above BAC concentrations values can be considered 'above background'- see Table $\mathrm{A}$ in the supplementary electronic material). PAH concentrations at or below the BC values are mapped in green, those above the $\mathrm{BAC}$ in red. Concentrations between these values are plotted in grey. Black bars are used for those PAHs where reference 
values have not been set. It should be noted that all such classifications are for guideline purposes only and are based on generic data.

\section{Biomarkers}

To demonstrate a possible way forward for future assessment of MHW, in terms of better integration of environmental data with biological 'health' we have trialled two biological response 'biomarkers' in mussels- metallothionein (MT -a measure of metal exposure) and TOSC (total oxyradical scavenging capacity- a measure of oxidative stress). A sub-sample of eight $M$. edulis in samples collected for contaminant analysis were dissected into gills and digestive glands. Each tissue sample was "flash-frozen" with liquid nitrogen in an Eppendorf tube, stored at $-70^{\circ} \mathrm{C}$ and processed as described by Chesman et al. (2007). Metallothionein was determined by differential pulse polarography (DPP) using a PARC model 174A analyser, and a PARC/EG\&G model 303 static mercury drop electrode. TOSC was determined in the same samples by measuring the suppression of ethylene formation by a system containing the peroxy-radical generator 2,2'-azobis-amidinopropane dihydrochloride and a labile substrate $\alpha$-keto- $\gamma$-methiolbutyric acid (Chesman et al., 2007).

\section{Results}

Metals

Maps of metals in M. edulis are shown in Figure 2 and those in C. edule, $N$. diversicolor, L. littorea and F. vesiculosus are included as supplementary electronic material (figures A-D). Species differences in body burdens and spatial trends are due to physiological and ecological attributes of individual bioindicators and the chemical properties of different metals. However, it is possible to make some general 
observations regarding bioavailability. Thus, in all species, Milford Haven body burdens were generally higher than those in the Tywi Estuary- the latter appeared to be a suitable regional estuarine reference site for most contaminants. One of the few exceptions concerns the slightly higher Mn burden in Nereis at the upper Tywi sediment site: this may reflect local sediment pore water conditions, particularly lower salinity (i.e. this apparent anomaly may be due to natural factors rather than contamination).

For the majority of metals and species, concentrations in $\mathrm{MH}$ biota were at the lower or middle part of the UK range (green and grey bars, respectively, in Figure 2 and Figures A-D in supplementary material; see legends for explanation).

Exceptionally, concentrations of a few elements in certain taxa of MHW were consistently at the higher end of the UK range (within the upper $25 \%$ of values, as represented by red bars in maps). These included As and Se in molluscs and seaweed. Also, as indicated in these figures, elevated levels were observed for individual sites/species: namely, Mn (molluscs, seaweed), Co (mussels, seaweed), Sn (bivalves), $\mathrm{Ni}$ (cockles) and Fe (ragworm).

Increases in bioavailability at upstream sites were evident in several metal-species combinations, which may reflect the influence of geogenic or other land-based sources. As with the example of Mn in Nereis, above, this pattern may be enhanced by the presence of lower salinities upstream (greater proportions of more bioavailable forms and less competition from chloride complexation). The strongest of gradients were seen for Cd (bivalves), Co (molluscs, seaweed), Mn (bivalves, seaweed), Ag, $\mathrm{Ni}$ (bivalves, ragworm, seaweed) and Sn (cockles, winkles). There was little indication of raised levels of bioaccumulation from sources in the lower part of Milford Haven. It is, perhaps, simplistic to generalise further over the status of metals in biota from the Haven but, by averaging percentiles across the range of species used, an overview 
of rankings (for maximum, minimum and mean values in the waterway) can be derived for each metal, in the context of UK ranges (Figure 3). The major features from this data treatment are that: (1) The upper concentrations of As and $\mathrm{Mn}$ at $\mathrm{MH}$ sites, averaged across all five study species (max percentiles, black bars in Figure 3), indicate that bioaccumulation is consistently high in UK terms, $(>80$ th percentile). Upper values for Co, Fe, Ni, Se and Sn were $>50^{\text {th }}$ percentile. (2) Mean levels in $\mathrm{MH}$ biota (grey bars, Figure 3) were $>$ 50th UK percentiles for As, Mn and Se confirming a widespread degree of contamination with these elements throughout much of the estuary. For most other metals, mean levels were close to or below the $25^{\text {th }}$ UK percentile. (3) Minimum concentrations in MH biota - usually at seaward sites -were within the lowest $10 \%$ of UK concentrations in most cases (white bars, Figure 3 ) and can be considered close to background. Exceptions were As, Mn (Se, Fe) implying some enrichment above background for these elements, even in the least contaminated parts of the Haven.

There is a broad similarity in the spatial patterns of metal bioaccumulation described here with earlier descriptions of sediment-metal distributions, in that highest sediment concentrations tend to be found upstream, whilst minimum values were generally those at the mouth of MH Waterway (Smith and Hobbs, 1994). Metal inputs probably occur along much of the waterway from sewage and industrial sources, though natural concentrating mechanisms (eg adsorption) can result in net transport of contaminated particles towards the head of the estuary. Here they combine with catchment sources, including a component from weathering of mineralized rocks $(\mathrm{Cu}, \mathrm{Pb}, \mathrm{Zn})$ and sulphide-rich coal measures (Se?). Exceptions to this geochemical trend do occur, however: for example, anomalously high sediment concentrations have occasionally been observed near the mouth of the Haven (e.g. $\mathrm{Cd}$ and $\mathrm{Hg}$ ), at the mouth of Cosheston Pill (Hg), and elsewhere, and appear to represent confined 'hotspots'. A 
landfill site at the industrial estate bordering Cosheston Pill (near Pembroke Ferry, Figure 1) may be responsible for this particular localized enrichment (Smith and Hobbs, 1994).

For physiological reasons however, sediment metal levels are not necessarily reflected in bioaccumulation. Copper, zinc (and lead) were considered by Smith and Hobbs (1994) to be substantially enriched in most of the MH sediments (compared with world-wide standard shale), partly as a consequence of anthropogenic inputs. In contrast, there were few indications of significant $\mathrm{Cu}$ or $\mathrm{Zn}$ enrichment in biota during the current study. This is not as contradictory as may appear, since many organisms have essential requirements for these elements and may regulate body burdens, thus underestimating environmental contamination. Lead levels in most biota sampled in the present survey were at the lower end of the UK range which may reflect declining levels from anthropogenic sources, notably following removal of alkyl lead from petrol.

The content of most other metals in MH sediments (Smith and Hobbs, 1994) were, with the exception of Co, typical of concentrations in UK estuaries (Bryan and Langston, 1992). Co enrichment in sediment from upstream sites in MHW may be indicative of catchment sources, probably natural in origin, and was reflected in the pattern of bioaccumulation in mussels and seaweed in the current survey.

Estimates made $20 \mathrm{y}$ ago indicated that the relative inputs of (organic) pollution to MHW were divided equally between freshwater, industrial and sewage discharges, though volumes were dominated by freshwater (96\%), of which the $\mathrm{W}$ and E Cleddau represented some $80 \%$ of total $\mathrm{FW}$ flow. Inputs of $\mathrm{Cu}, \mathrm{Pb}$ and $\mathrm{Zn}$ from these two rivers were estimated at 336, 336, $1000 \mathrm{~kg} \mathrm{y}^{-1}$ and $381,381,1300 \mathrm{~kg} \mathrm{y}^{-1}$, respectively (Hobbs and Morgan, 1992; Bent, 2000). Atmospheric discharges from Pembroke Power Station (1993) were estimated to be 4.4 (As), <300 (Cd, Cr, Cu), $6600(\mathrm{Fe})$ 
$13600(\mathrm{Ni})$ and $65300(\mathrm{~V}) \mathrm{kg} \mathrm{y}^{-1}$. Less than $1 \%$ of total pollutant load was estimated to come from road run-off. Contaminated land/ landfill inputs are potential, as yet unquantified sources. Likewise, budgets for $\mathrm{Cu}$ and $\mathrm{Zn}$ leaching from antifouling are unknown. More accurate and updated loadings estimates for contaminants would be useful in terms of identifying specific sources of bioaccumulation.

Results from the few previously published studies do not indicate exceptional metal bioaccumulation in $\mathrm{MH}$ biota, in agreement with the current data. Mussel samples from 1996 and 1997 collected at St Ishmaels, near Dale (Widdows et al., 2002) are most relevant to our 2008 survey. Taking the 1996 results as baselines, recent As and $\mathrm{Hg}$ concentrations were higher, by $50 \%$ and $200 \%$, respectively. In contrast, there have been consistent declines for $\mathrm{Cd}, \mathrm{Ni}, \mathrm{Se}(50-100 \%)$ and, to a small extent, for $\mathrm{Cu}$ $(\sim 20 \%)$

Earlier (1993-5) biomonitoring with seaweeds, as part of the EA (NRA) Welsh Region Marine Biological Programme (Davies and Ellery, 1995), included analyses of $\mathrm{Cd}, \mathrm{Cu}$ and $\mathrm{Zn}$ at Dale and Lawrenny $(\mathrm{MH})$, together with Ferryside in the Tywi (used in the current survey, Figure 1) and comparisons are plotted in Figure 4. During the intervening period, $\mathrm{Cd}$ concentrations throughout the area dropped by $\sim 50-60 \%$ (comparable to trends in mussels). This reduction in $\mathrm{Cd}$ bioaccumulation is presumably in response to controls on Cd inputs in the wider area (including major sources in the Severn Estuary). Copper concentrations have also dropped, by $\sim 30 \%$, at MH sites and by $>60 \%$ in the Tywi (though the 1995 data appear to have been exceptionally high). In contrast, changes in $\mathrm{Zn}$ concentrations have been relatively small over the last 15 years (Figure 4). 


\section{TBT and other organotins}

Organotin (OT) burdens in mussels are displayed in Figure 5 (see also table B, supplementary material). Butyltin (TBT, DBT, MBT) concentrations mostly increased upstream. The exception was a relatively high value for MBT at Dale. When compared with OSPAR Environmental Assessment Criteria (EAC), TBT concentrations were above the lower EAC but below the upper EAC. In contrast, TBT concentrations (and other BTs) in mussels from the Tywi reference site were close to zero.

The proportion of $\sum \mathrm{BT}(\mathrm{TBT}+\mathrm{DBT}+\mathrm{MBT})$ present in environmental samples as the parent compound, TBT, is an indication of the relative importance of recent sources (a high proportion of TBT indicates fresh inputs). In the current survey, the proportion of TBT varied from $12 \%$ at Dale to almost $50 \%$ at Pembroke Ferry (mean 31\%). In contrast, mussels from the reference site in the Tywi Estuary contained $<1 \%$ TBT with most of the BT burden present as the breakdown product MBT. This implies that the influence of recently introduced TBT was greatest in the vicinity of Pembroke Ferry and lowest at the reference site.

The concentrations of phenyltins in mussels were much lower than butyltins (TPT and DPT are shown in Figure 5, MPT was below detection). This pattern probably reflects the low usage of TPT as an antifouling agent, compared with TBT. Nevertheless, the pattern of TPT distribution in mussels closely resembles that of TBT. The proportion of total PT present as the parent compound, TPT, varied from $66-100 \%$ in $\mathrm{MH}$ (mean $81 \%$ ), compared with $29 \%$ at the Tywi reference site. Again this infers more recent input to the MHW and that phenyl tins, though present at lower concentrations than butyltins, may persist for longer before degradation.

In their survey of mussel condition around the Irish Sea in 1996/7, Widdows et al., (2002) found that the concentrations of OT were generally low at coastal sites but 
elevated near harbours, with $\Sigma$ BT concentrations ranging from 'not detected' to 0.66 $\mu \mathrm{g} \mathrm{g}^{-1}$ dry wt. The highest value on the UK mainland occurred in MH mussels - from St. Ishmaels, in the vicinity of the oil terminal (Widdows et al., 2002). The reported concentrations of TBT $\left(0.44 \mu \mathrm{g} \mathrm{g}^{-1}\right)$ were above the threshold of $0.2 \mu \mathrm{g} \mathrm{g}^{-1}$ at which uncoupling of oxidative phosphorylation, the primary mechanism of toxicity, commences. The maximum TBT concentration in the current study was $0.12 \mu \mathrm{g} \mathrm{g}^{-1}$ (Pembroke Ferry). Whilst not threatening the survival of mussels, accumulated body burdens of this order would represent a challenge to the reproductive success of TBTsensitive neogastropods such as dogwhelks Nucella lapillus. Previous surveys have indicated that TBT body burdens and imposex in $N$. lapillus were generally highest near the central and outer part of Milford Haven (where tankers moor), decreasing (with anomalies) seaward (Harding et al., 1998). Neyland Marina, opposite Pembroke Ferry, has also previously been identified as a TBT 'hotspot', whilst upstream, TBT levels in the Cleddau were considered typical of UK estuaries (Kitts, 1999; Bent, 2000).

Maximum BT values in MH mussels in 1996/7 (Widdows et al., 2002), were higher than any of the current values: TBT and DBT concentrations at Dale are now almost $100 \%$ lower than those previously recorded at nearby St. Ishmaels. Theoretically, the global ban on TBT in 2008 should start to produce a further decline in TBT contamination. The current data set is therefore a timely and suitable platform to test this hypothesis and to establish the rate of recovery.

Organotin concentrations in the ragworm $N$. diversicolor (see Table B and figure E, supplementary information) display somewhat different spatial distributions to those in mussels for a number of possible reasons, including the fact that they live and feed in benthic sediments. Bioavailability of TBT in this phase may influence body burdens to a greater extent than filter feeding mussels whose main source of TBT is 
probably the overlying water (including suspended organic matter). Secondly, the sites at which $N$. diversicolor were collected were slightly different to mussel sites. $N$. diversicolor may also be better at metabolizing TBT to DBT and MBT. Thus, concentrations of TBT in $N$. diversicolor were on average fourfold lower than in mussels.

In contrast to mussels, the average triphenyltin (TPT) concentration in worms was five-fold higher than that in mussels (DPT seventy-fold higher), consistent with observations that phenyltins partition more strongly towards sediment and might therefore be more available to sediment-dwelling species. Additionally, the Nereis site with highest TPT (and MPT) levels, at Pembroke (Waterloo), was within Cosheston Pill -and perhaps subjected to localized sources, compared with the nearest mussel site (Pembroke Ferry) in the main waterway. The use of TPT in antifouling has been less extensive than TBT in the UK; however, phenyltins have in the past also been used in agriculture as pesticides and fungicides.

PCBs

Results summarizing biomonitoring of PCBs in Mytilus edulis and Nereis diversicolor based on analysis of the $\sum$ ICES 7 congeners (CBs 28, 52, 101, 118, 138, 153 and 180) are plotted in Figure 6 (see also table C, supplementary material). Concentrations in MH mussels showed an unexpected spatial trend in that highest values occurred at the mouth of the Haven and decreased in an upstream direction: The lowest values here were comparable to the reference site in the Tywi Estuary. Manufacture of PCBs has long since ceased and it seems unlikely that there are recent discharges of any significance which influence distribution. Rather, biotic factors may be involved since PCB concentrations in mussels follow a pattern which is similar to the condition index (below). It may be that body burdens of these lipophilic contaminants are a 
function of lipid reserves which would be anticipated, from condition data, to be highest in those populations at the seaward end of the waterway.

The lower and higher OSPAR environmental assessment criteria (EAC) for $\sum$ ICES7 PCBs in mussel are 5 and $50 \mu \mathrm{g} \mathrm{kg}^{-1} \mathrm{dw}$ and all values for Milford Haven and Tywi samples were below the upper threshold (above which effects on marine species might be expected), but exceeded the lower 'no-effects' threshold (OSPAR, 2004; NMMP, 2004). These EACs are only guidelines to ecotoxicological impact - and may be set with over-precautionary 'safety factors': nevertheless, the results indicate that supplementary biological effects studies would be appropriate.

Some context is gained by comparison of PCB values in $N$. diversicolor from $\mathrm{MH}$ with others from the Severn Estuary (table 2). For the lower chlorinated congeners, concentrations in both systems were relatively low: for the more highly chlorinated CBs 138, 153 and 180 (hexa- and hepta-chlorobiphenyls), and total PCBs, there was considerably more bioaccumulation in the Severn (on average almost 20 -fold for $\sum \mathrm{CBs}$ ). This excess in the Severn is not unexpected, since PCBs were previously manufactured at in the region at Newport, a known hotspot for contamination.

There are few comparative PCB data from earlier surveys. Concentrations of $\sum 25$ PCB congeners (composition not stated), determined in mussels from Milford Haven (St Ishmaels) in 1996/7, were in the range 0.009-0.013 $\mu \mathrm{g} \mathrm{g}^{-1}$ (Widdows et al., 2002). These were somewhat lower than values determined in the current study. In contrast, concentrations in mussels from hotspots in the Irish Sea, such as Liverpool Bay and the Mersey Estuary, were an order of magnitude higher (Widdows et al., 2002).

PAHs

PAH concentrations in $M$. edulis sampled during the current project are tabulated in the supplementary data (table D). Some of the key features are illustrated in Figure 7. 
For many PAHs, including 1-methyl-naphthalene, acenaphthene, anthracene, chrysene, perylene, benzo(ghi)perylene, ideno(1,2,3-cd)pyrene, benzo(k)fluoranthene, benzo(b)fluoranthene, benzo(a)anthracene and benzo(a)pyrene (latter shown in figure 7), body burdens were elevated in the central and upper parts of $\mathrm{MH}$ and were higher than the Tywi reference site (this applies also to $\sum \mathrm{PAHs}$ ).

However, for several PAHs (fluorene, phenanthrene, fluoranthene, and pyrene) concentrations were not substantially different across the sites (example shown in figure 7 is pyrene). It appears that distributions fall into groupings which may reflect their similarity in origins and chemistry.

Placed in the context of OSPAR Background Concentrations (BC) and Background Assessment Criteria (BAC) for mussels, levels above background (BAC) are observed widely for phenanthrene, fluoranthene, benzo(a)anthracene, benzo(ghi)perylene, benzo(a)pyrene and pyrene (see examples for latter two PAHs in figure 7; bars depicted in red are above background (>BAC); green bars represent concentrations characteristic of undeveloped sites (BC); grey bars lie in between). There were a few PAH concentrations which would be considered as background and representative of undeveloped sites (see, for example, anthracene Figure 7). Again it is stressed that these comparisons are guidelines only, not proof of ecotoxicological threat. Despite evidence of bioaccumulation of most PAHs in mussels, acute effects are not expected from the body burdens measured; in reality, however, the true extent of combined sub-lethal effects from these and other compounds is unknown and requires assessment.

Distributions of several PAHs in Nereis diversicolor were similar to those in M.edulis (see supplementary data, table D); subtle differences could be due in part to localized sampling site differences between the two species and the stronger influence of sediment contamination on $N$. diversicolor. Species differences in the activity of 
enzymes which metabolise PAHs (e.g. cytochrome P450 system) will also contribute to the variation in bioaccumulation patterns. The main conclusions drawn from PAHs in Nereis were that Milford Haven body burdens were often higher than at the Tywi reference site, with enrichment most notable for naphthalene and 1-methylnaphthalene, especially upstream. Acenaphthene, fluoranthene, pyrene, benzo(a)anthracene and chrysene were characterized by elevated levels at Dale. A third group (fluorene, phenanthrene, anthracene, benzo(b)fluoranthene, indeno (1,2,3cd) pyrene) was typified by a more even distribution across all sites, including the Tywi reference site.

Results for PAHs in $N$. diversicolor from $\mathrm{MH}$ have been compared with data for the Severn Estuary, with ratios for individual PAHs shown in table 3, indicating that Severn worms contained higher levels than those in Milford Haven - particularly so for the higher molecular weight PAHs. Only phenanthrene was higher in Nereis from MH. ¿PAHs were on average three-fold higher in worms from the Severn Estuary.

To place mussel data in similar perspective, the pattern in $\mathrm{PAH}$ bioaccumulation in M.edulis along the Bristol Channel/Severn Estuary was established in a study of benzo(a)pyrene $(\mathrm{BaP})$ residues conducted after the Sea Empress grounding in $\mathrm{MH}$ in 1996 (CEFAS, 2000; Law et al., 1999). An increase in BaP bioaccumulation in mussels eastwards from the Mouth of $\mathrm{MH}$, towards Cardiff, was tentatively related to the trend in urban development along the coastline and to the delivery of PAHs from the Severn catchment upstream. PAH enrichment in mussels from the Severn, relative to that in Milford Haven, therefore mirrors the pattern in Nereis.

Sources of PAHs in Severn Estuary have included the south Wales coalfield, oil bearing shales in Bridgwater Bay, combustion of fossil fuels, land run-off and the precipitation of airborne particulates. As a result, sediments in the Severn were considered moderately high in PAHs in a survey of UK coastal sites conducted by 
Woodhead et al. (1999), though the highest value was obtained from Milford Haven. Correspondingly, $\sum 18$ PAHs in MH mussels at the time of the Sea Empress oil spill rose to extremely high levels within a few days at sites such as Angle and Dale (26189 -100946 $\mu \mathrm{g} \mathrm{kg}^{-1} \mathrm{ww}$ ) though within three months these had dropped back by $>90 \%$ (to $500 \mu \mathrm{g} \mathrm{kg}^{-1} \mathrm{ww}$ ) notably for oil-derived PAHs like naphthalene and phenanthrene and their alkylated derivatives (Dyrynda et al., 2000). Current $\sum$ PAH values at Angle and Dale indicated further reductions and were 30 and $18 \mu \mathrm{g} \mathrm{kg}^{-1} \mathrm{ww}$, respectively.

Pyrogenic PAHs exhibited somewhat different temporal behaviours following the grounding of the tanker (Law et al., 1999; Dyrynda et al., 2000). Bioaccumulation in mussels peaked 23 days after the February spill (up to $\sim 80 \mu \mathrm{g} \mathrm{kg}^{-1} \mathrm{ww}$ ), before declining close to zero in mid-summer. One year post-spill, further small seasonal (winter) peaks in combustion-derived (high molecular weight) PAHs, such as benzoa-pyrene $(\mathrm{BaP})$, indeno[1,2,3-cd] pyrene and benzo[ghi] perylene ${ }^{\dagger}$ were observed in mussels from Dale and Angle (upto $\sim 40 \mu \mathrm{g} \mathrm{BaP} \mathrm{kg}^{-1}$ ww at the latter site), before returning to baseline levels of a few $\mu \mathrm{g} \mathrm{kg}^{-1}\left(<1 \mu \mathrm{g} \mathrm{BaP} \mathrm{kg}{ }^{-1}\right.$ ww in the current survey).

Similar seasonal patterns have been observed for pyrogenic PAHs in N Sea mussels (reaffirming that PAH bioaccumulation is not always related to oil spillage, and may influenced by biotic as well as physicochemical and climatic factors such as run-off and precipitation). The return to lower PAH levels in spring may also be a function of depuration and losses during spawning (gonadal tissues are enriched in PAHs relative to other tissues), subsequent rapid growth (dilution), and perhaps increased photodegradation. Though metabolism of hydrocarbons is considered to be relatively

\footnotetext{
$\uparrow$ Other combustion derived PAHs include anthracene, fluoranthene, pyrene, benzanthracenes, chrysene, benzofluoranthenes. There was also an indication of a peak in immunosupression effects in these mussels, coinciding with raised PAHs. Dyrynda et al., 2000)
} 
limited in molluscs, this ability will tend to rise with seasonally increasing temperatures (Law et al., 1999; Dyrynda et al., 2000). The samples taken in our survey of Milford Haven, in March, would coincide with the maxima in pyrogenic PAHs described previously.

\section{Discussion}

Integrating bioaccumulation, environmental and biological response data -the way forward?

Biometric data for M. edulis and C. edule are expressed in terms of condition indices (CI) in the current survey, with higher values signifying better condition. Thus the CI of mussel (a measure of tissue weight relative to shell length) is shown in Figure 8A. Highest values were those at St Ishmael (SI -the reference site in the Tywi) and at Angle Bay (A) in the lower Haven. All other samples in MH were significantly lower than the reference site, SI, with values generally lowest upstream from Pembroke Ferry (PF). The CI of whole cockles is shown in Figure 8B and resembles strongly the pattern in mussels. Highest values were those at St Ishmael (the reference site in the Tywi) and at Dale; CI decreased upstream in the Cleddau Estuary.

Correlation coefficients between CI and metals in mussels indicate several significant (negative) relationships (Table 4) with CI decreasing according to the sequence $\mathrm{Pb}>\mathrm{Se}>\mathrm{Cu}>\mathrm{Zn}>\mathrm{Hg}>\mathrm{Ni}$. (The corresponding sequence for metals in cockles was $\mathrm{Co}>\mathrm{Ni}>\mathrm{Hg}=\mathrm{As}>\mathrm{Se}>\mathrm{Mn}>\mathrm{Cu}=\mathrm{Fe})$.

For mussels it is possible to extend the range of contaminants in these comparisons to include PAHs, PCBs and organotins. The ranking of contaminants, for those which are significantly (negatively) correlated with CI, is shown in Table 4. Some of the more toxic (e.g. $\mathrm{Pb}, \mathrm{TBT}, \mathrm{Cu}$, benzo(a)pyrene) appear high on this list and it seems plausible that a combination of contaminants could have an influence on CI. 
Multivariate analysis of Milford Haven data

Body burdens of a number of contaminants co-vary illustrating possible common sources. However, such covariance contributes to the difficulty in attributing cause and effect. There are also other factors which may be influential in the condition of bivalves; notably feeding rate, food availability and salinity. There is a strong case to attempt better co-ordination of chemical and biological monitoring in future. To establish cause and effect more substantially would require additional measurements of sub-lethal effects and environmental parameters, coupled with multivariate statistical techniques to try and tease out the relative importance of these parameters. We have attempted to illustrate the benefits of this approach by including measurements of sample biomarkers TOSC (total oxyradical scavenging capacity - a measure of oxidative stress) and MT (metallothionein - a metal binding protein synthesised to protect organisms from excess intracellular metal) in MH mussels. These have been analysed alongside other biological (CI) and chemical variables (body burdens of metals, organotins, $\sum$ PAHs and $\sum$ PCBs), using the PRIMER-E statistical package to examine the principle components responsible for site distinctiveness and to demonstrate a possible way forward for future assessment.

This principal component analysis (PCA) approach enables reduction of complex multivariate data to a much simpler representation of 'similarity' i.e. which sites are most similar to, or different from, each other. Normalisation was performed so that each variable has equal weighting in the final PCA ordination which reduces the location of each sample to a best-fitting 2-D or 3-D solution. A sample 2-D PCA plot for mussels is shown in Figure 9 and represents $58.5 \%$ of the variation, while $3-\mathrm{D}$ ordination captures $72.7 \%$. There is approximately equal (positive) contribution to PC1 from each of the metals and organotins, together with (negative) contributions 
from some of the biometric data (weight and condition index). PC2 is dominated by eigenvectors representing $\sum$ PAHs (positive) and digestive gland TOSC (negative).

Figure 9 appears cluttered due to superimposition of the eigenvectors for each variable (shown as individual axes), but shows how the different sampling sites relate to each other within this dimensionally-reduced multivariate space. Clearly the 'control' site (St Ishmael, Tywi) on the bottom left of the plot, is distant from most of the other sites. By considering the eigenvectors, this appears largely to be due to a combination of low metals, low hydrocarbons and PCBs, high levels of digestive gland TOSC (high capacity to scavenge oxyradicals) and high levels of biometrics (size, weight and condition index). Collectively this indicates that mussels from the St Ishmael reference were generally larger, in good condition, with low levels of accumulated contaminants and high capacity to cope with pollutant-induced stress.

Outer sites in Milford Haven - Dale and Angle - also separated from inner estuary sites in Figure 9. Dale is at a similar level to St Ishmael on PC2 (hydrocarbons, PCBs and DG TOSC) but further to the right on PC1 indicating higher metal burdens and lower biometrics. In contrast, at Angle, across the waterway there appears to be slightly less influence of metals, but much higher effect of hydrocarbons and PCBs together with a reduction in DG TOSC.

Pennar Mouth, the entrance to the Pembroke River, sits between Dale and Angle in Figure 9, although it shows greatest similarity with Angle, probably reflecting the influence of hydrocarbons and PCBs at this site.

The remaining inner estuary sites fall on the right-hand side of the PCA ordination, with an overall tendency for the most upstream sites to lie towards the bottom of the plot. The location of these sites on the right would appear to result principally from the combined accumulation of metals and organotins together with metallotheionein induction in mussels, while the vertical 'zonation' results from the components in PC2 
(principally total hydrocarbons, PCBs and DG TOSC, although the eigenvectors show that several metals also exert influence in this direction as well).

There is a risk in 'over-analysing' PCA plots when determining the factors that best describe the similarities or differences seen between sites, since PCA is a simplification of the true multivariate data. Given these caveats, it may be regarded that overall, in Figure 9, there is an increasing level of contaminant impact and biological response moving from bottom-left to top right across the PCA plot. Sites closest to each other (in the PCA plot, but not necessarily geographically) are the most similar, while, conversely, those furthest apart are most different in terms of the parameters measured in mussels during this survey.

One consideration for the future is to link biological community data, bioaccumulation, biomarkers and environmental variable data, which will require that harmonised sampling is conducted. This linked data may be useful to generate compatible datasets so that we may better understand the principal drivers acting on the biota in Milford Haven.

\section{Acknowledgements}

The authors are grateful to the members of the Milford Haven Waterways Group (MHWESG) for their support for this work and in particular to Dr Blaise Bullimore and Captain Mark Andrews for their guidance and suggestions. Thanks are also due to Nia Watkins for help with sampling and to Dr Hiroya Harino for contributions to analysis.

\section{Bibliography}

Atkins (2005). Development of an Inputs Budget for Milford Haven Waterway. Technical report to the MHWESG. 
Bent, E. (2000). A review of environmental studies in Milford Haven Waterway 19922000. Report to the MHWESG.

Bryan, G.W., Langston, W.J., Hummerstone, L.G., and Burt, G.R.(1985). A guide to the assessment of heavy-metal contamination in estuaries using biological indicators, Mar. Biol. Ass. U.K., Occasional Publication No. 4, 92 pp.

Burton, S. (2006). Pembrokeshire Marine Special Area of Conservation: Draft management scheme. $157 \mathrm{pp}$.

CEFAS (2000) Monitoring and surveillance of non-radioactive contaminants in the aquatic environment and activities regulating the disposal of wastes at sea. Aquatic Environment Monitoring Report, 52, 92pp.

Chesman, B.S., O' Hara, S., Burt G.R. and Langston W.J. (2007). Hepatic metallothionein and total oxyradical scavenging capacity in Atlantic cod Gadus morhua caged in open sea contamination gradients. Aquatic Toxicology, 84, 310-320.

Davies, G. and Ellery, S. (1995). Results of the NRA Welsh Region marine bioaccumulation programme 1991-1995. NRA Report No. SE/EAU/95/9

Dyrynda, E.A., Law, R.J., Dyrynda, P.E.J., Kelly, C.A., Pipe, R.K. and Ratcliffe, N.A. (2000). Changes in immune parameters of natural mussel Mytilus edulis populations following a major oil spill ('Sea Empress', Wales, UK). Marine Ecology Progress Series, 206, 155-170.

Harino, H., O'Hara, S.C.M., Burt, G.R., Chesman, B.S. and Langston, W.J. (2005). Accumulation of butyltin compounds in benthic biota of the Mersey Estuary. Marine Pollution Bulletin, 50(2), 223-226. 
Hobbs, G and Morgan, C I (eds.) (1992). A review of the current state of environmental knowledge of the Milford Haven Waterway. Report to the Milford Haven Waterway Environmental Monitoring Steering Group. 140pp.

Langston, W.J. and Spence, S.K. (1995). Biological Factors involved in metal concentrations observed in aquatic organisms. In: Metal Speciation and Bioavailability, Tessier A. and Turner D.R. (Eds), John Wiley and Sons Ltd., $407-478$

Langston, W.J., Bryan, G.W., Burt, G.R. and Pope, N.D. (1994a) Effects of sediment metals on estuarine benthic organisms. Project Record, National Rivers Authority , 49pp.

Langston, W.J., Bryan, G.W., Burt, G.R.(1994b). Heavy metals in UK estuaries:PML data and mapping programme,R\&D Note 280, National Rivers Authority, 85pp.

Law, R.J., Thain, J.E., Kirby, M.F., Allen, Y.T., Lyons, B.P., Kelly, C.A. et al. (1998). The impact of the Sea Empress oil spill on fish and shellfish. In: The Sea Empress oil spill, Edwards, R and Sime, H. (Eds), pp 109-136. Lavenham: Lavenham Press

Law, R.J., Kelly, C.A. and Nicholson, M.D. (1999). Polycyclic aromatic hydrocarbons (PAH) in shellfish affected by the Sea Empress oil spill in Wales in 1996. Polycyclic Aromatic Compounds, 17(1-4), 229-239.

Lundebye, A.K., Langston, W.J. \& Depledge. M.H. (1997) stress proteins and condition index as biomarkers of TBT exposure. Ecotoxicology, 6, 127-136

Nelson-Smith, A. (1965). Marine biology of Milford Haven: The physical environment. Field Stud., 2 (2): 155-188. 
Nikitik, C.C.S. and Robinson, A.W. (2003). Patterns in benthic populations in the Milford Haven Waterway following the Sea Empress oil spill with special reference to amphipods. Mar. Pollut. Bull. 46, 1125-1141.

NMMP (2004). UK National Marine Monitoring Programme. Second Report (19992001). Marine Environment Monitoring Group, CEFAS, ISBN 090754520 3, $136 \mathrm{pp}$.

OSPAR (2000). Quality Status Report 2000 for the North-East Atlantic. OSPAR Commission, London, 108+viipp.

OSPAR (2004). OSPAR/ICES Workshop on the evaluation and update of background reference concentrations $(\mathrm{B} / \mathrm{RCs})$ and ecotoxicological assessment criteria (EACs) and how these assessment tools should be used in assessing contaminants in water, sediment and biota. Hazardous Substances Series. ISBN 1-904426-52-2, 167pp.

OSPAR (2007). 2006/2007 CEMP Assessment: Trends and concentrations of selected hazardous substances in the marine environment. Assessment and Monitoring Series. Publication Number: 330/2007, 63pp.

Rostron, D. (1998). Sea Empress sediment shore impact assessment monitoring: Infauna of heavily oiled shores in Milford Haven and Carmarthen Bay. A report to the Countryside Council for Wales from SubSea Survey, Pembroke. 51pp + appendices.

Smith, J. and Hobbs, G. (1994). Metal concentrations in Milford Haven sea bed sediments - data storage, analysis and initial interpretation. Field Studies Research Council Research Centre FSC/RC/12/94, 8pp+ appendices

Vane, C.H., Harrison, I. and Kim, A. (2007). Assessment of polyaromatic hydrocarbons (PAHs) and polychlorinated biphenyls (PCBs) in surface 
sediments of the Inner Clyde Estuary, UK. Marine Pollution Bulletin, 54, 13011306.

Widdows, J., Donkin, P., Staff, F.J., Matthiessen, P., Law, R. J., Allen, Y. T., Thain, J. E., Allchin, C. R. and Jones, B.R. (2002). Measurement of stress effects (scope for growth) and contaminant levels in mussels (Mytilus edulis) collected from the Irish Sea. Marine Environmental Research, 53, 327-356.

Woodhead, R.J., Law R.J. \& Matthiessen P. (1999). Polycyclic aromatic hydrocarbons in surface sediments around England and Wales, and their possible biological significance. Marine Pollution Bulletin 38, 773-790. 


\section{FIGURES}

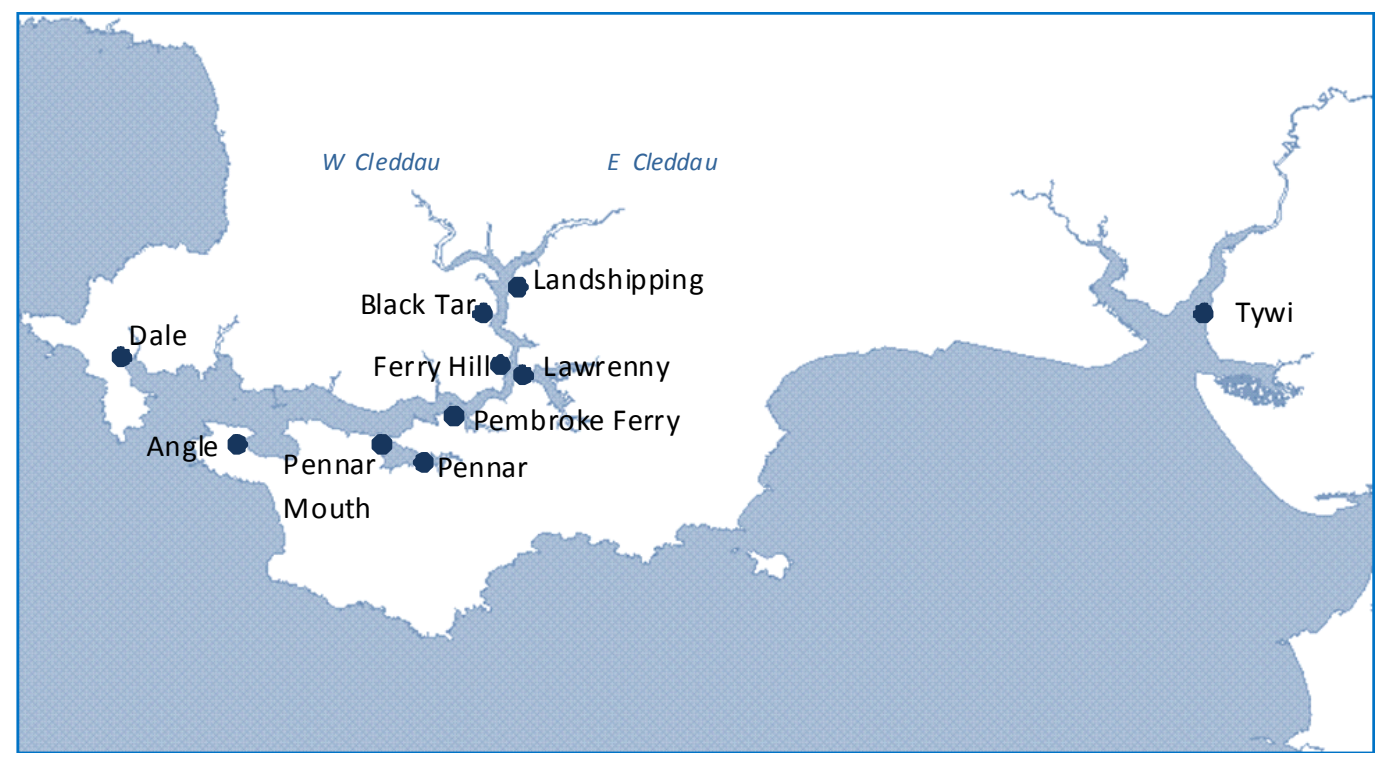

Figure 1 Location of sampling sites for biota, Milford Haven and Tywi Estuary 


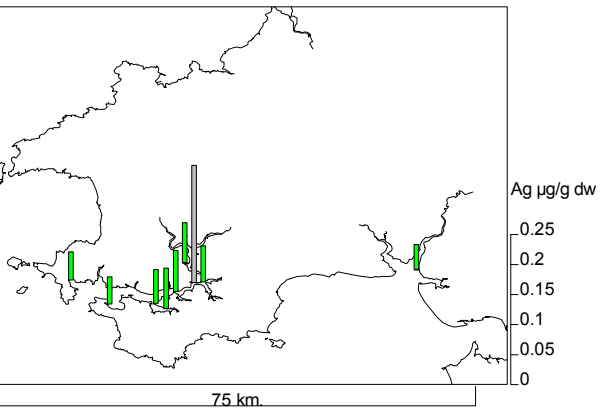

Ca Mussels

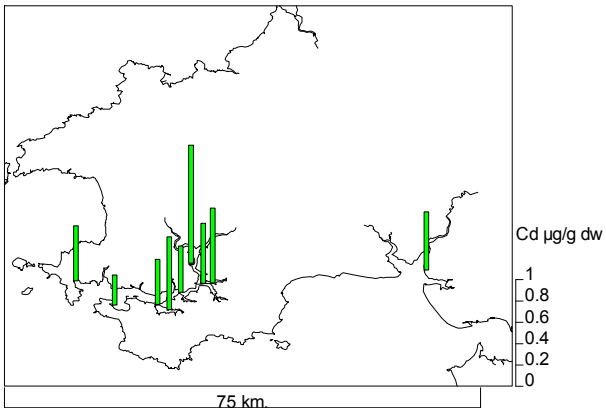

Cr Mussels

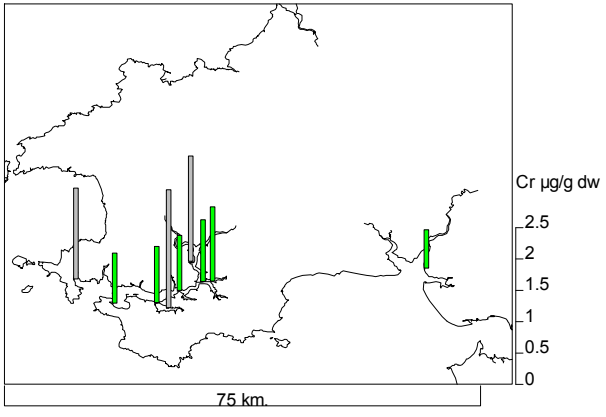

Fe Mussels

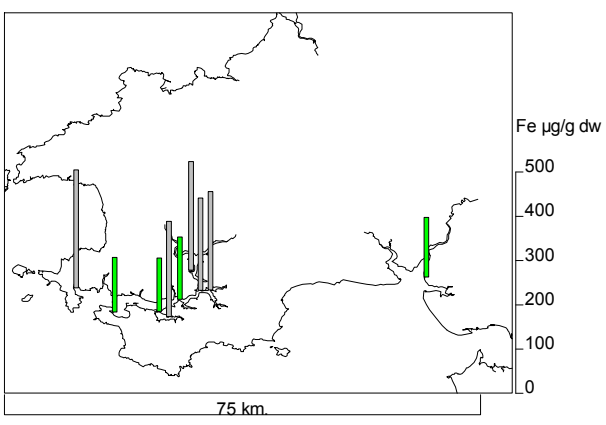

As Mussels

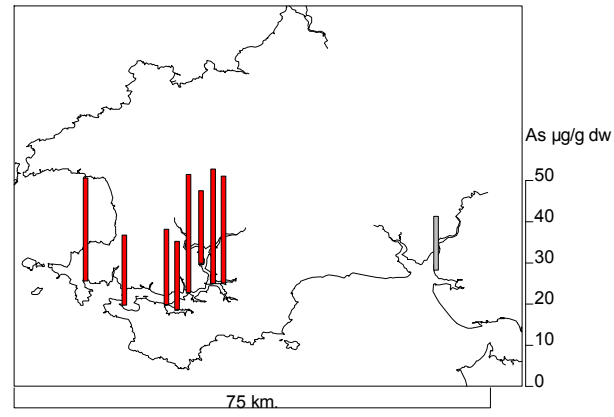

Co Mussels

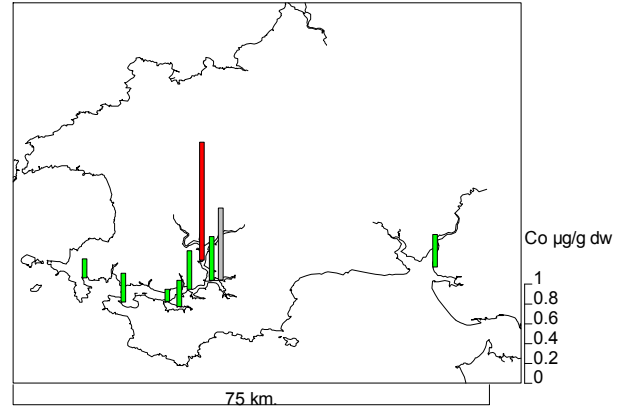

Cu Mussels

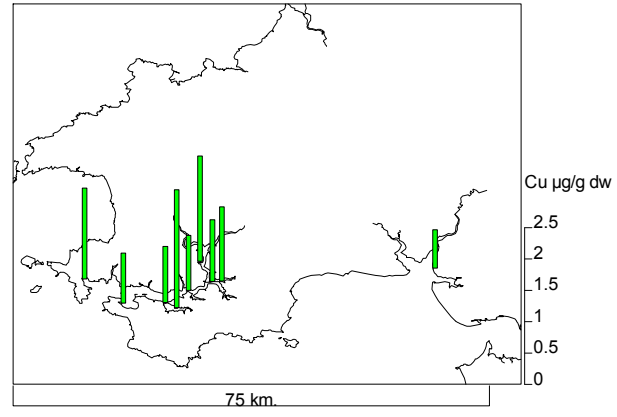

Hg Mussels

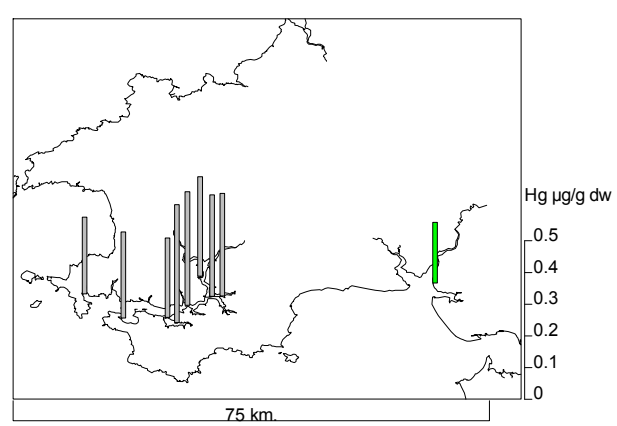

Figure 2. Metals in mussels Mytilus edulis, $\mu \mathrm{g} \mathrm{g}^{-1}$ dry weight. Values below the lower quartile value (lowest $25 \%$ ) of values in MBA UK data base are plotted as green bars and red if above the upper quartile (highest $25 \%$ ). Values in the mid range $\left(25-75^{\text {th }}\right.$ percentile) are represented as grey bars. (cont.)...... 


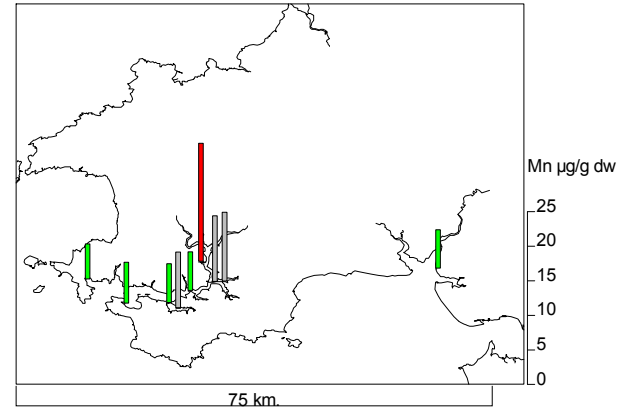

$\mathrm{Pb}$ Mussels

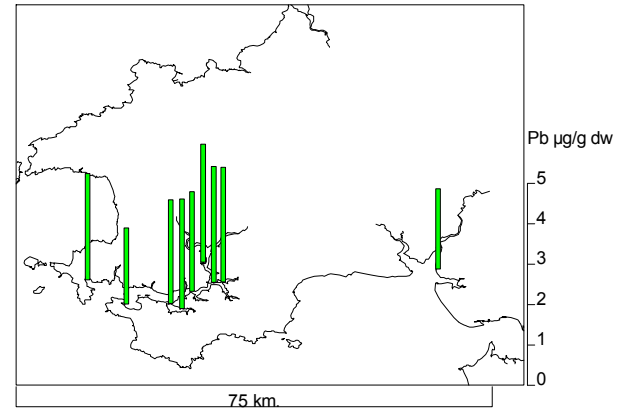

Sn Mussels

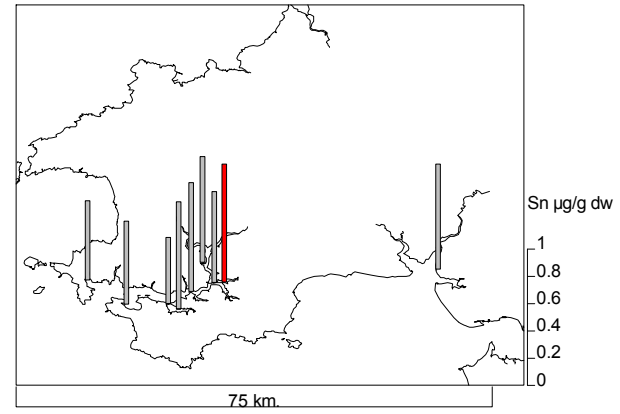

Ni Mussels

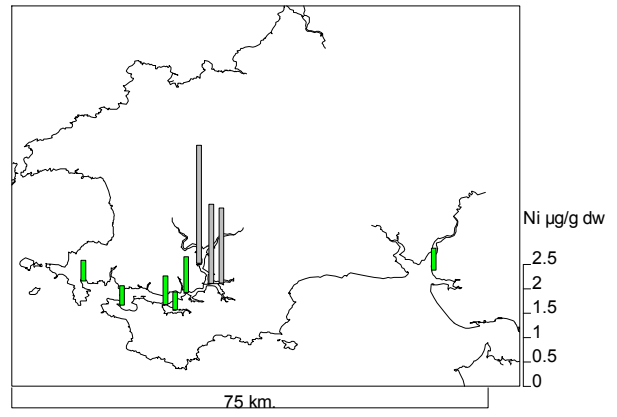

Se Mussels

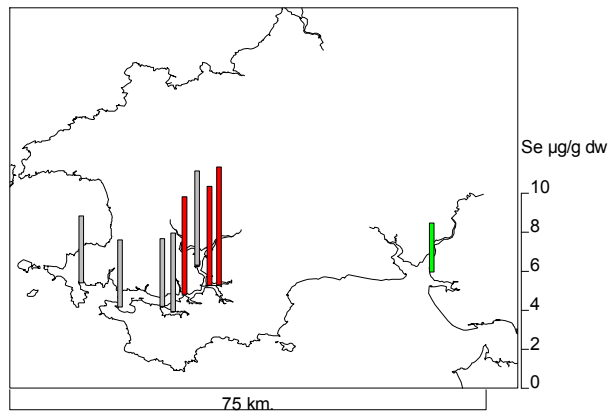

Zn Mussels

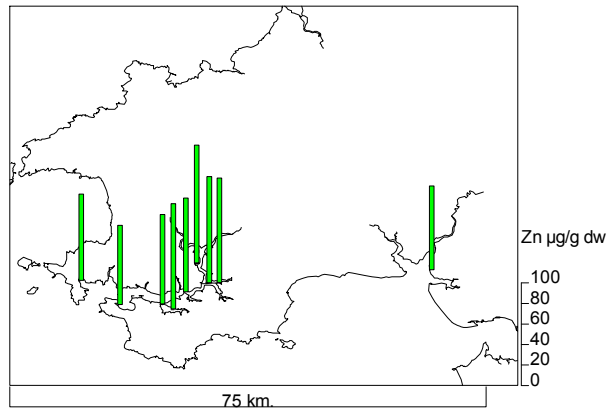

...Figure 2 (cont.). Metals in mussels Mytilus edulis, $\mu \mathrm{gg}^{-1} \mathbf{d w}$. Values below the lower quartile value (lowest $25 \%$ ) of values in MBA UK data base are plotted as green bars and red if above the upper quartile (highest $25 \%$ ). Values in the midrange $\left(25-75^{\text {th }}\right.$ percentile) are represented as grey bars. 


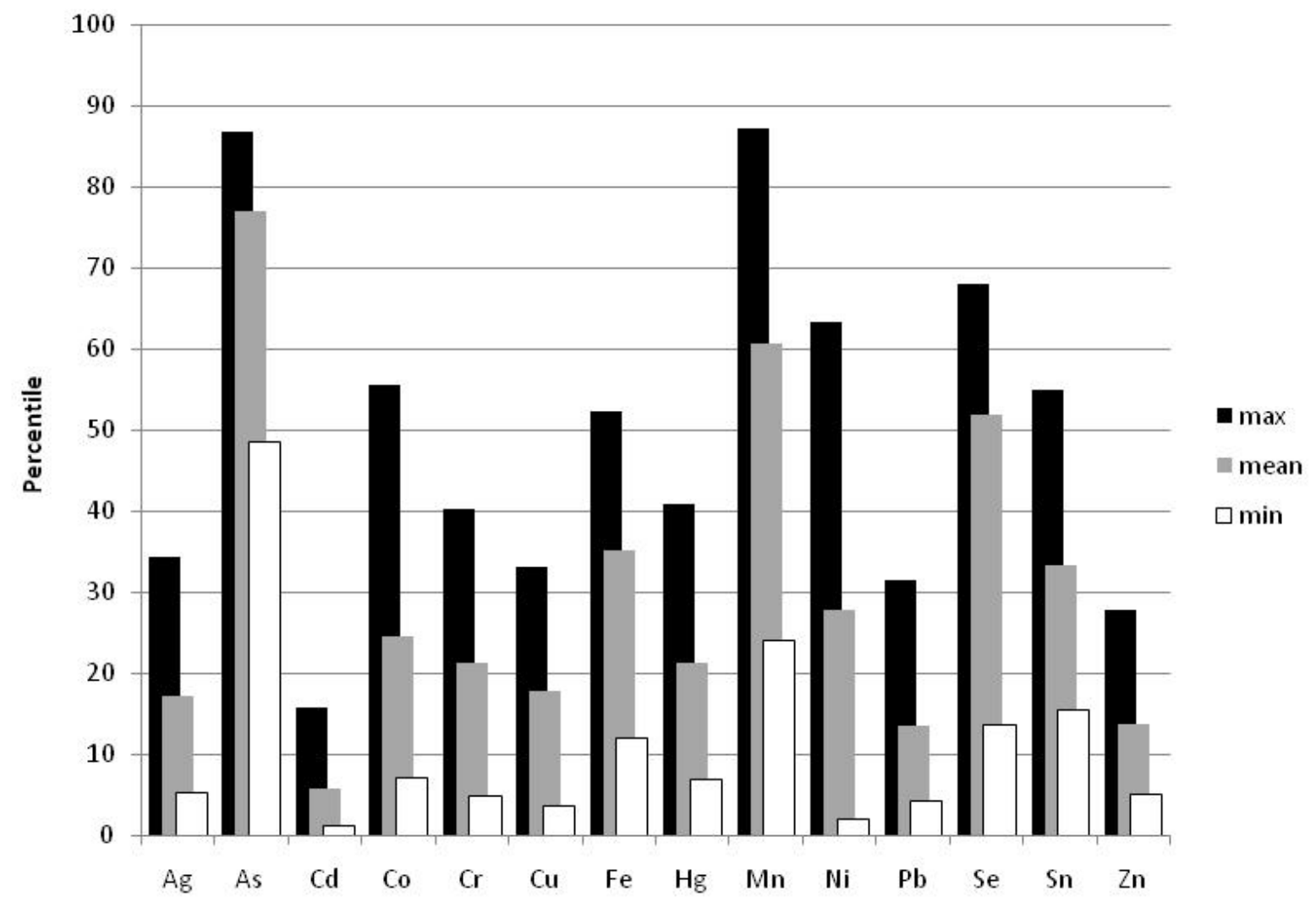

Figure 3. Metals in Milford Haven biota 2007/8. Minimum, maximum and mean values expressed as percentiles of UK ranges (averaged across Fucus vesiculosus, Littorina littorea, Mytilus edulis, Cerastoderma edule and Nereis diversicolor). 

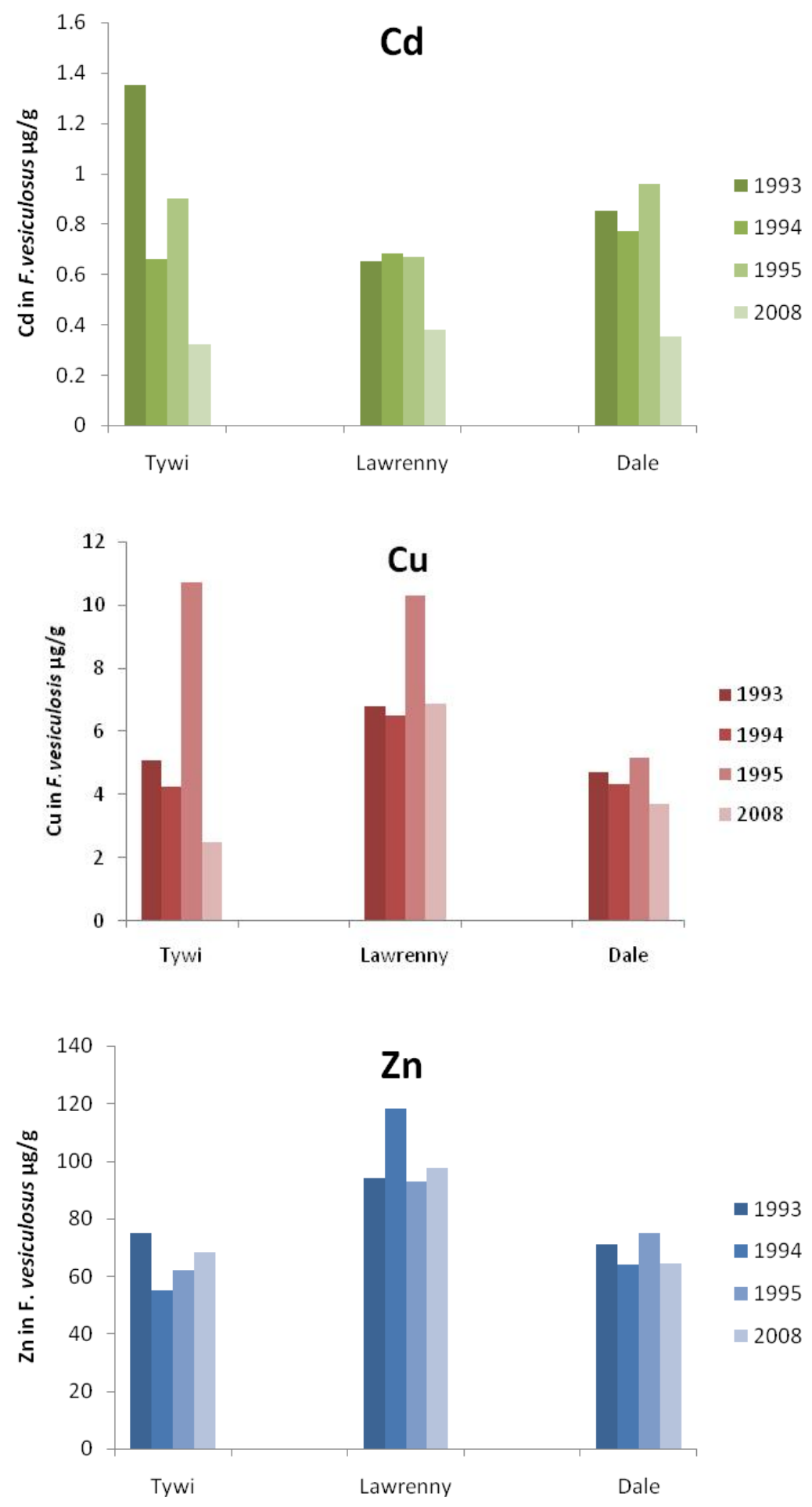

Figure 4. Fucus vesiculosus: metal concentrations measured in the current survey at Lawrenny and Dale (MH) and the Tywi reference site, compared with concentrations determined in the previous decade by Davies and Ellery, 1995). 
TBT Mussel

based on OSPAR EAC criteria (2004)

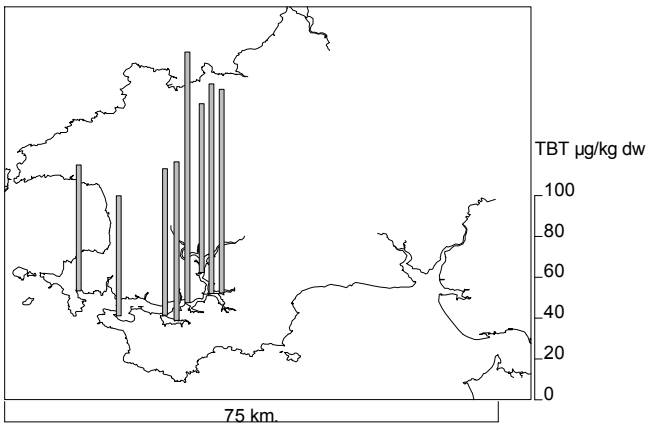

DBT Mussels

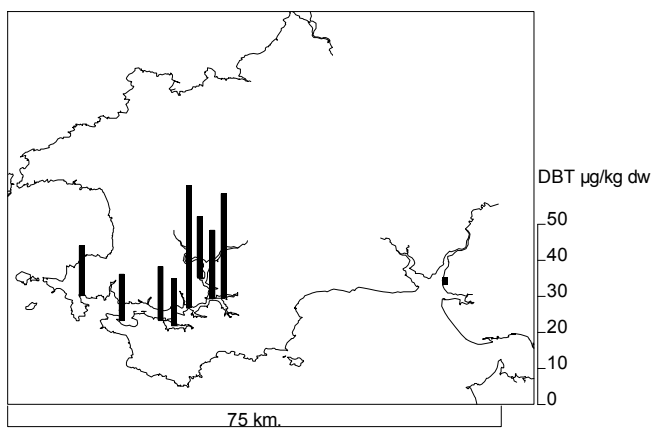

MBT Mussels

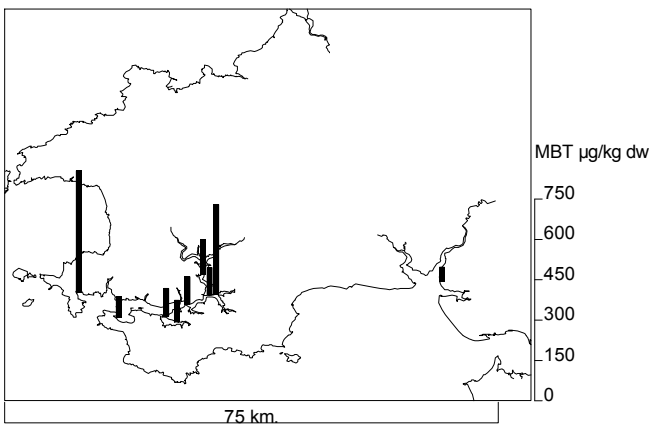

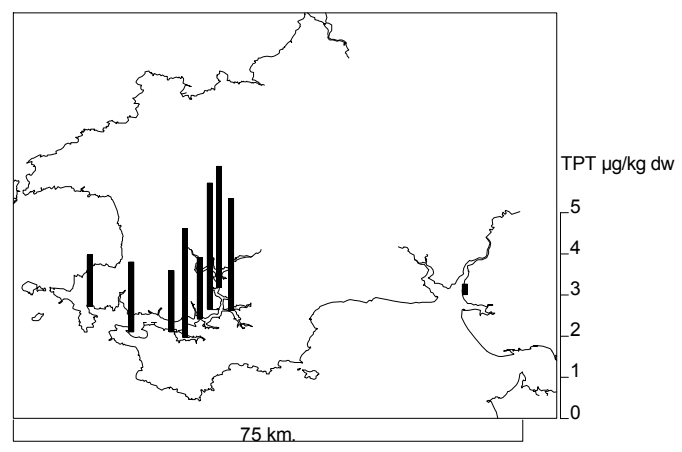

DPT Mussels

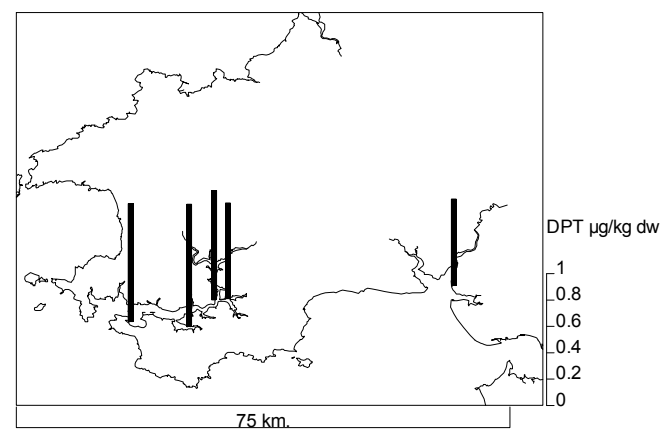

Figure 5. Organotin concentrations $\left(\mu \mathrm{g} \mathrm{kg}^{-1} \mathrm{dw}\right)$ in mussels Mytilus edulis

Total PCBs Mussels

using OSPAR EAC criteria

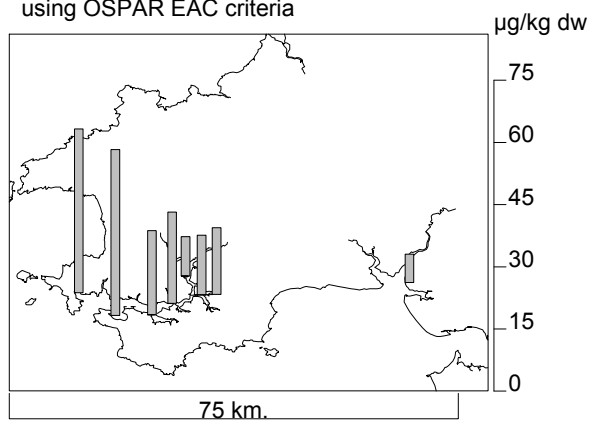

Total PCB Nereis

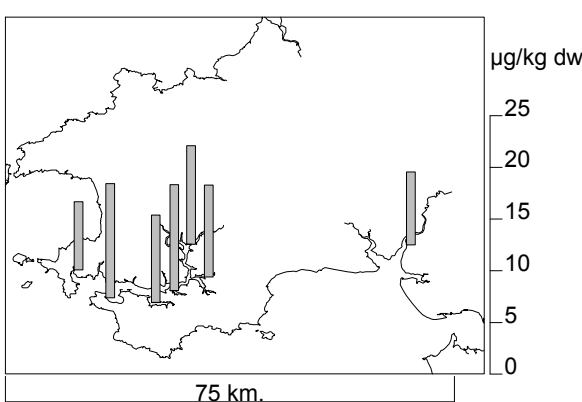

Figure 6. PCBs ( $\sum$ ICES 7 congeners) in mussels Mytilus edulis and ragworm Nereis diversicolor. 

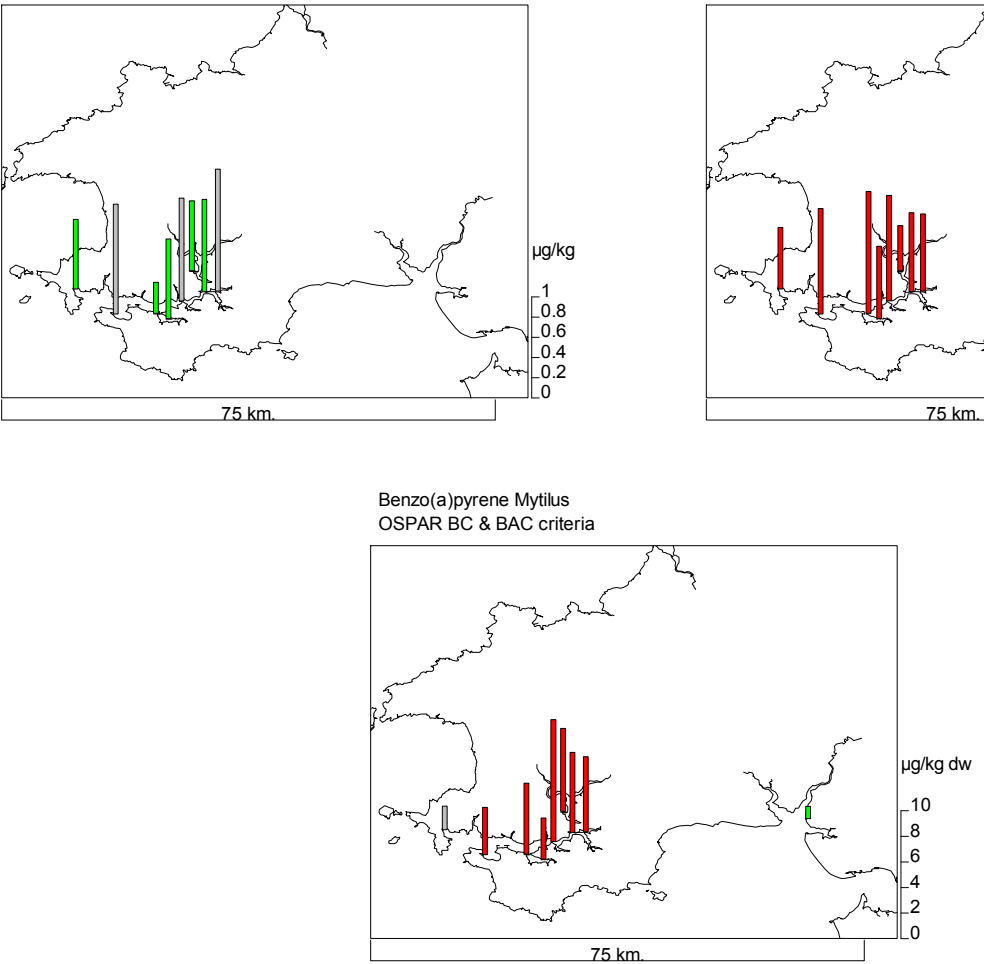

Figure 7. PAHs in Mytilus edulis in context of Background Concentration (BC) and Background Assessment Criteria (BAC) for mussels. Bars depicted in red are above background (BAC); green bars represent concentrations characteristic of undeveloped sites (BC); grey bars lie in between.

A

Mussel whole tissue condition index (4) - Milford Haven March 2008 comparison with "reference site" St Ishmael (SI) Tywi Estuary

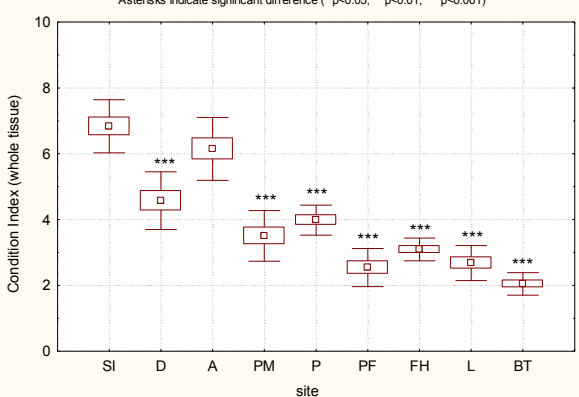

B

Condition Index whole cockles March 2008

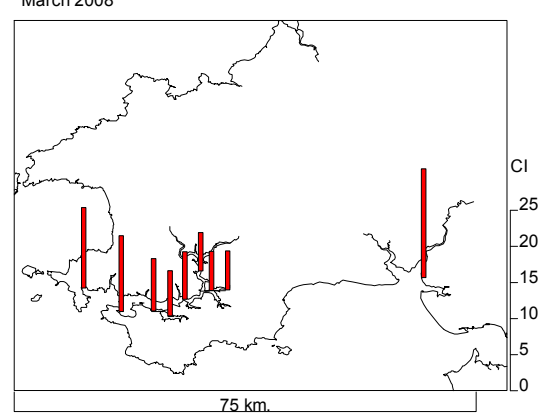

Figure 8. Condition indices in bivalves: (A) Mytilus edulis (B) Cerastoderma edule ( ${ }^{*}$ Sites significantly different to the Tywi reference site at St Ishmael (SI). Other labels D-Dale; A-Angle; PM- Pennar Mouth; P-Pennar; PFPembroke Ferry; FH-Ferry Hill; L-Lawrenny; BT- Black Tar). 


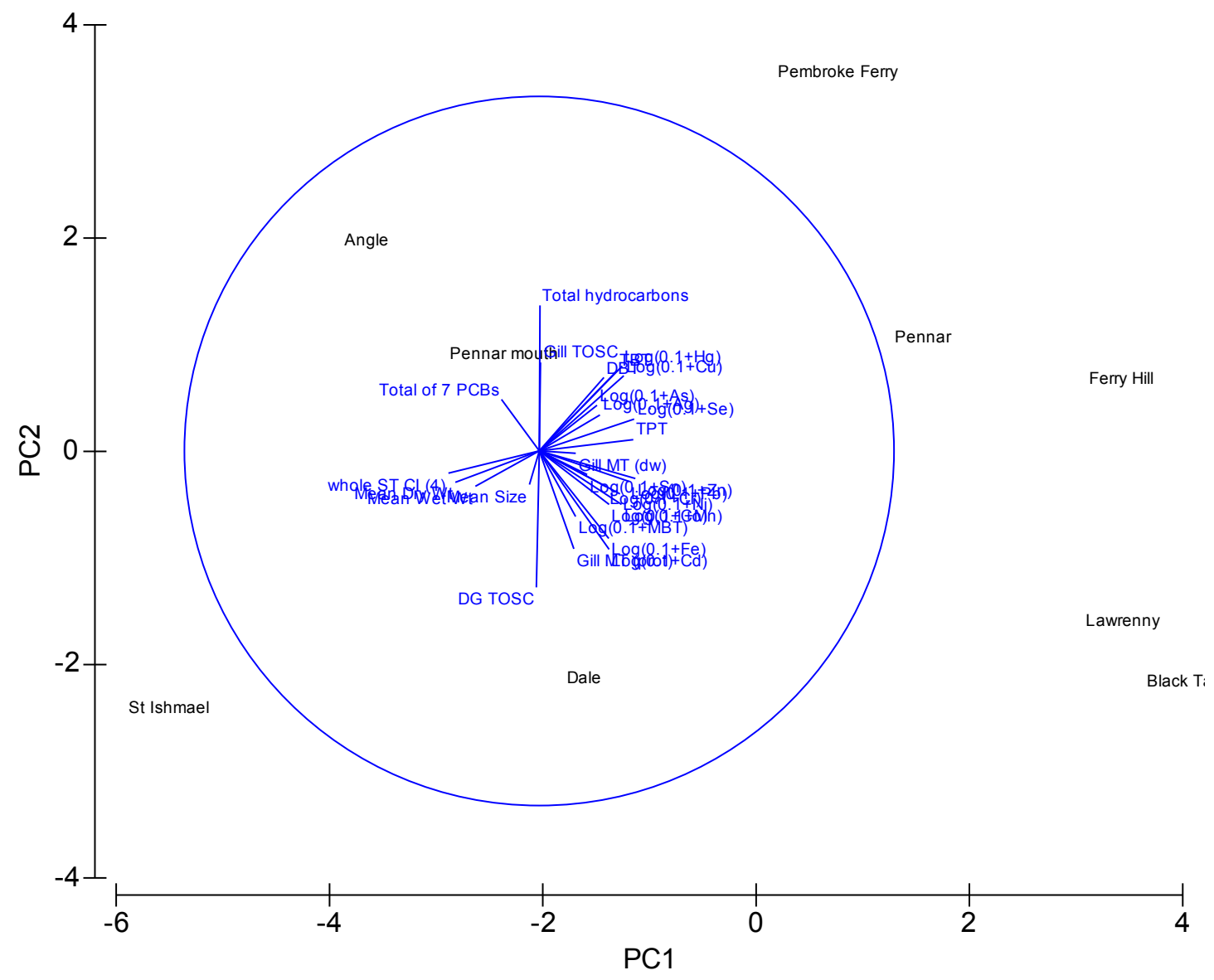

Figure 9. 2-dimensional PCA ordination of Milford Haven mussel data. Eigenvectors for individual variables (contaminants, biomarkers, biometrics) are indicated. Locations of sampling sites in the diagram show how they relate to each other within this dimensionally-reduced multivariate space. 


\section{TABLES}

Table 1. Summary of sampling sites and species distributions

\begin{tabular}{|c|c|c|c|c|c|c|}
\hline Site & Map ref (sites sampled) & Fuc & Ner & Lit & Myt & Cer \\
\hline \multicolumn{7}{|c|}{ MILFORD HAVEN WATERWAY } \\
\hline Landshipping & SN011118 & $(+)$ & ++ & $(+)$ & $(+)$ & $(+)$ \\
\hline Landshipping Quay & SN008108 & $(++)$ & & ++ & $(+)$ & $(+)$ \\
\hline Black Tar & SM999093 & ++ & & $(+)$ & ++ & ++ \\
\hline Lawrenny (Cresswell/Carew Mouth) & SN017063 & + & ++ & & & \\
\hline Lawrenny (Jenkin’s Point) & SN009062 & ++ & & ++ & ++ & ++ \\
\hline Ferry Hill & SN003061 & ++ & & $(+)$ & ++ & ++ \\
\hline Pembroke Ferry (Waterloo) & SM982040 & ++ & ++ & ++ & & \\
\hline Pembroke Ferry (Ferry Inn) & SM974047 & ++ & & $(+)$ & ++ & ++ \\
\hline Pembroke River (Pennar) & SM959020 & ++ & ++ & ++ & ++ & ++ \\
\hline Pembroke River (Pennar Mouth) & SM943028 & ++ & & $(+)$ & ++ & ++ \\
\hline Angle Bay ${ }^{b}$ & SM870027 & ++ & & ++ & ++ & ++ \\
\hline Angle Bay $^{\mathrm{a}}$ & SM868028 & & ++ & & & \\
\hline Dale $^{b}$ & SM809065 & ++ & & ++ & ++ & ++ \\
\hline Dale $^{\mathrm{a}}$ & SM815075 & & ++ & & & \\
\hline \multicolumn{7}{|c|}{ TYWI REFERENCE SAMPLES } \\
\hline Tywi (1.2km u/s of Ferryside) & SN370117 & & ++ & & & $(+)$ \\
\hline Tywi (St. Ishmael) & SN361082 & ++ & & ++ & ++ & + \\
\hline
\end{tabular}

Key: Fuc, Fucus vesiculosus; Ner, Nereis diversicolor; Lit, Littorina littorea; Myt, Mytilus edulis; Cer, Cerastoderma edule. + species present and sampled. ++ species numerous and sampled. $(+)$ species present, but not sampled (in some cases, specimens too small or sparse).

Table 2. Nereis diversicolor. Comparison of CBs in Milford Haven samples with those in the Severn Estuary.

\begin{tabular}{cccccccc}
\multicolumn{7}{c}{ Ratios Severn Estuary: Milford Haven } \\
CB028 & CB052 & CB101 & CB118 & CB138 & CB153 & CB180 & $\sum$ CBs \\
0.5 & 1.0 & 2.5 & 6.7 & 12.9 & 10.9 & 28.0 & 18.7
\end{tabular}

Table 3. Nereis diversicolor. Comparison of PAHs in Milford Haven samples with those in the Severn Estuary.

Ratios Severn estuary : Milford Haven

\begin{tabular}{|c|c|c|c|c|c|c|c|c|c|}
\hline Naphthalene & Phenanthrene & Anthracene & Fluoranthene & Pyrene & $\begin{array}{c}\text { Benzo[a]- } \\
\text { anthracene }\end{array}$ & Chrysene & $\begin{array}{c}\text { Benzo[a]- } \\
\text { pyrene }\end{array}$ & $\begin{array}{l}\text { Benzo[ghi]- } \\
\text { perylene }\end{array}$ & $\begin{array}{l}\text { Indeno[1,2,3- } \\
\text { cd]pyrene }\end{array}$ \\
\hline 25 & 0.85 & 7.7 & 2.5 & 6.4 & 14 & 13 & 24 & 48 & 110 \\
\hline
\end{tabular}


Table 4. Mytilus edulis. Comparison of (negative) Correlation coefficients between Condition Index and metal body burdens (all values are significant, $\mathrm{P}<0.05$; ns not significant; nd not determined)

\begin{tabular}{lc} 
contaminant & Correlation with Condition Index \\
\hline Pb & -0.86325 \\
TBT & -0.85835 \\
Se & -0.83187 \\
Benzo(a)pyrene & -0.80803 \\
Cu & -0.80061 \\
Zn & -0.78868 \\
Benzo(ghi)perylene & -0.78032 \\
DBT & -0.75958 \\
Dibenzo(ah)anthracene & -0.74688 \\
Perylene & -0.74128 \\
Hg & -0.69862 \\
Benzo(k)fluoranthene & -0.69206 \\
Ni & -0.68709 \\
\hline
\end{tabular}


Ag Cockles

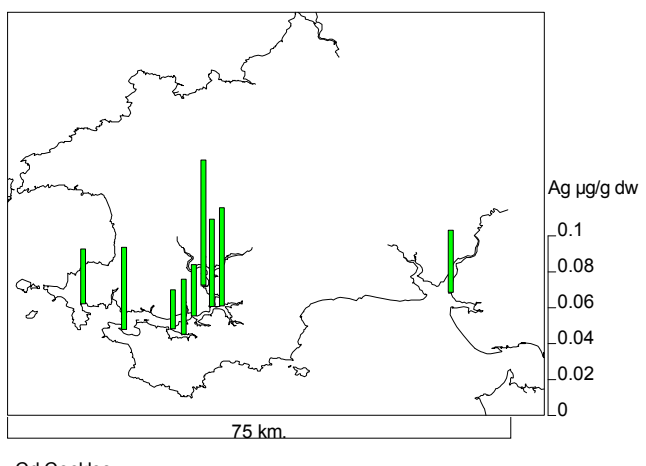

Cd Cockles

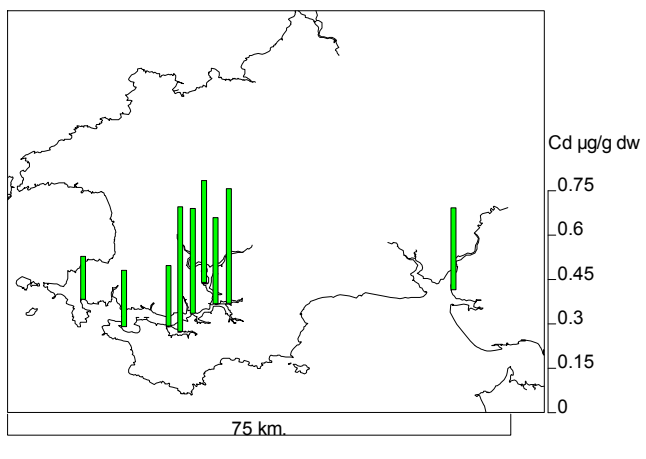

Cr Cockles

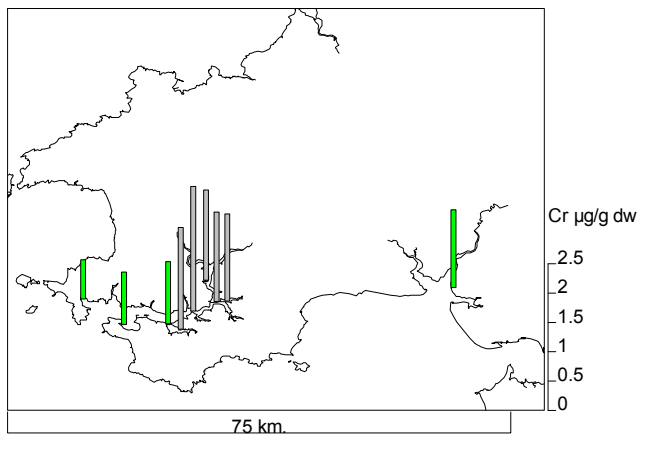

Fe Cockles

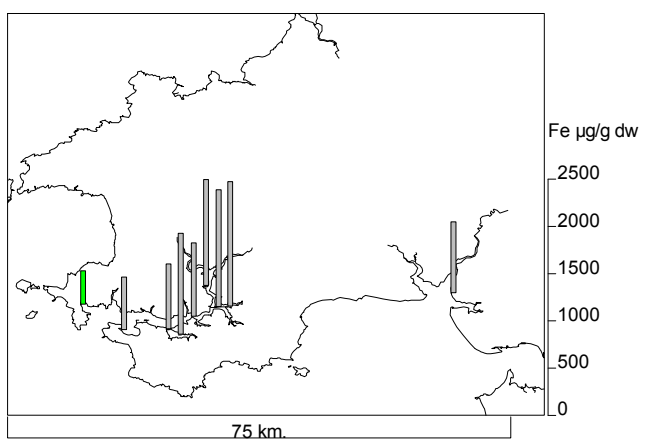

As Cockles

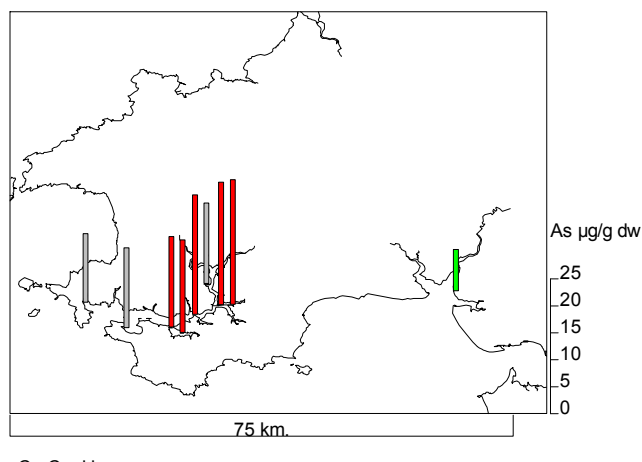

Co Cockles

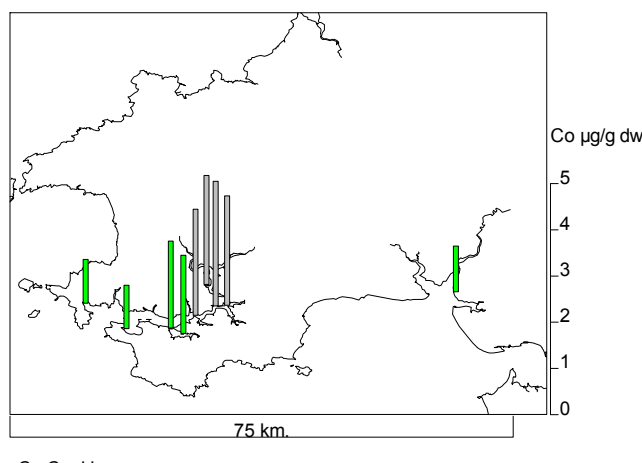

Cu Cockles

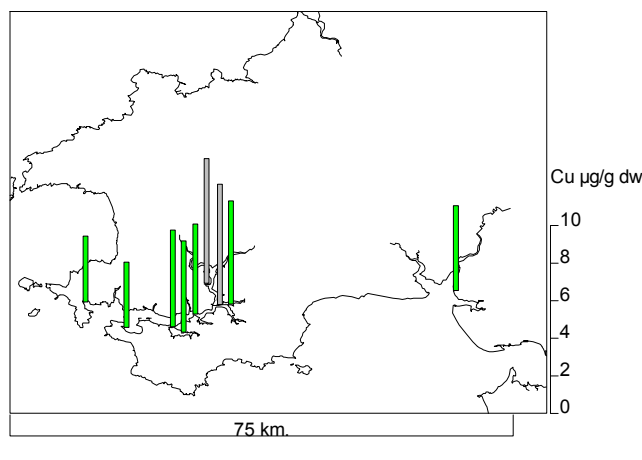

Hg Cockles

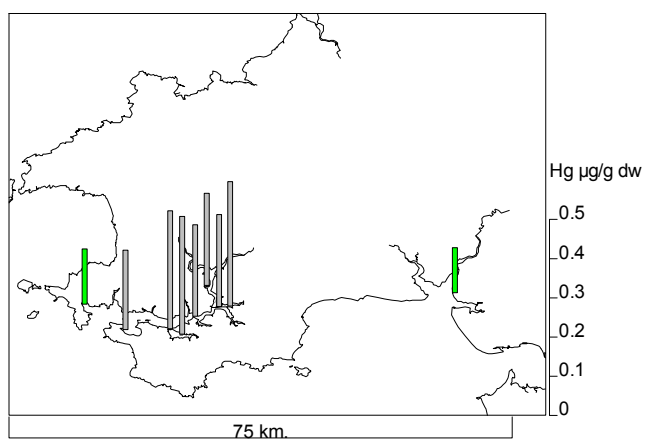

Figure A. Metals in cockles Cerastoderma edule, $\mu \mathrm{g}^{-1} \mathrm{dw}$. Values below the lower quartile value (lowest 25\%) of values in MBA UK data base are plotted as green bars and red if above the upper quartile (highest $25 \%$ ). Values in the mid-range $\left(25-75^{\text {th }}\right.$ percentile) are represented as grey bars (cont.).... 

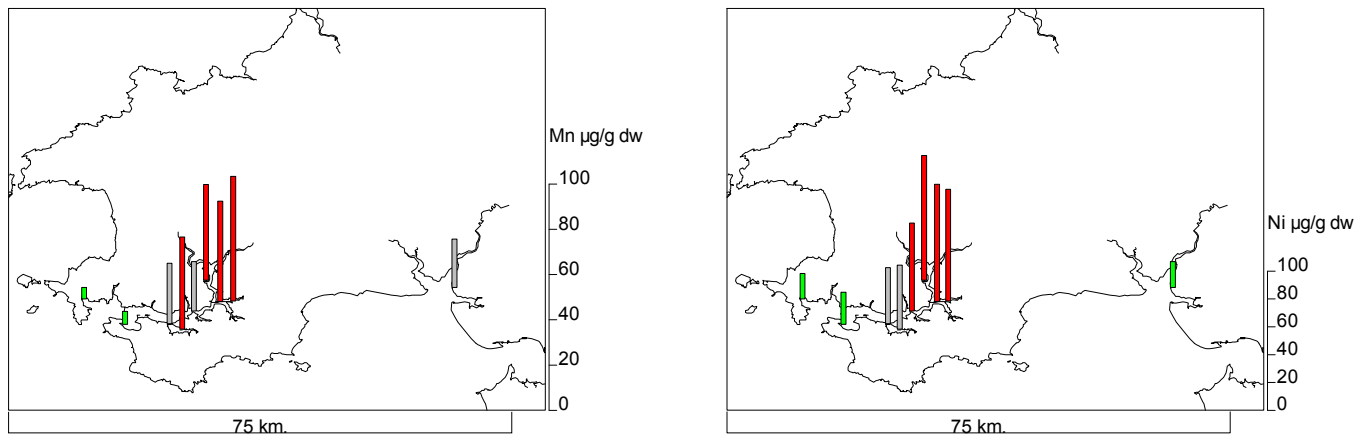

$\mathrm{Pb}$ Cockles

Se Cockles
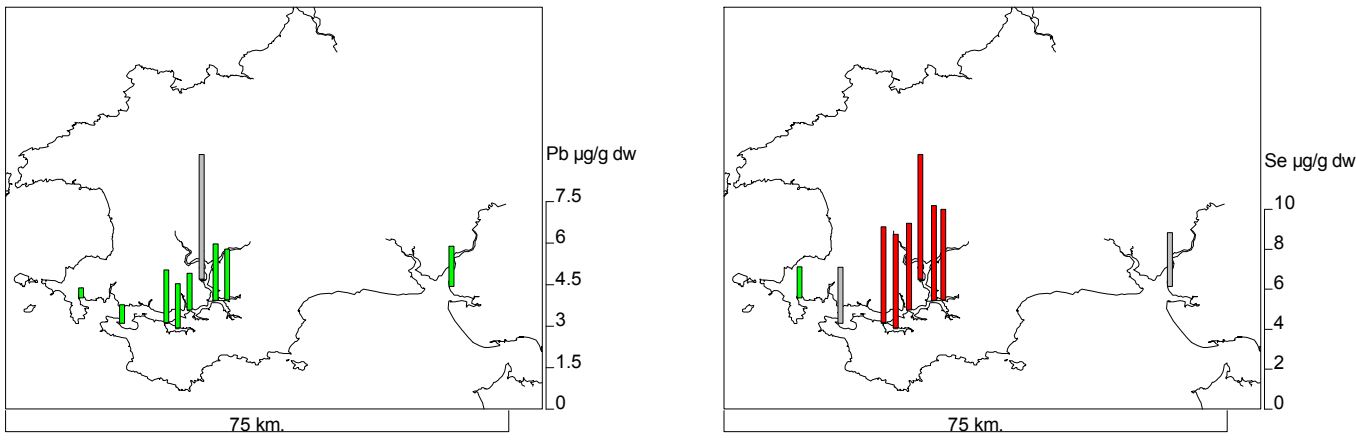

Sn Cockles

Zn Cockles
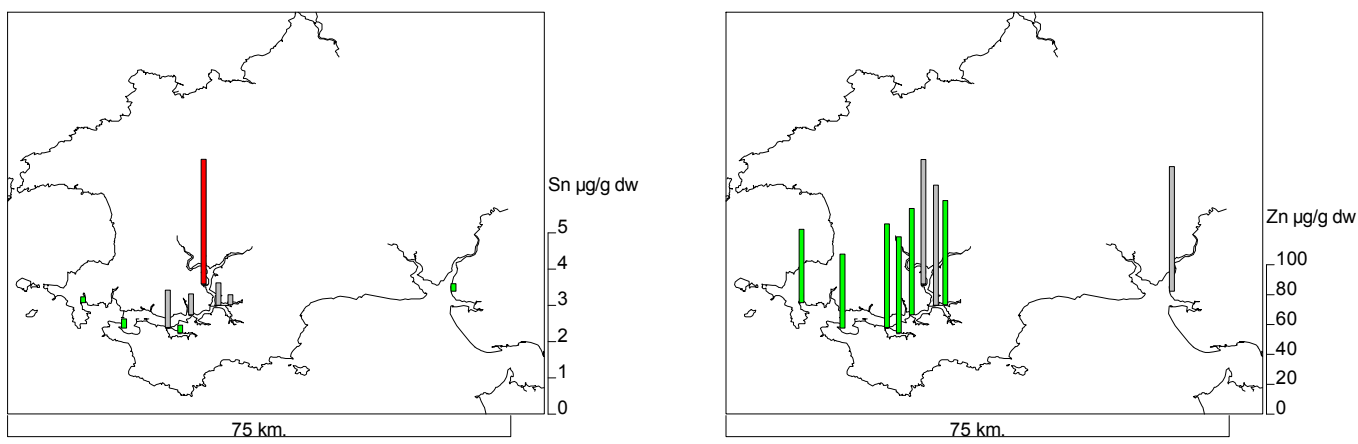

...Figure A(cont.). Metals in cockles Cerastoderma edule, $\mu_{\mathrm{g}} \mathrm{g}^{-1} \mathrm{dw}$. Values below the lower quartile value (lowest $25 \%$ ) of values in MBA UK data base are plotted as green bars and red if above the upper quartile (highest $25 \%)$. Values in the mid range $\left(25-75^{\text {th }}\right.$ percentile) are represented as grey bars. 

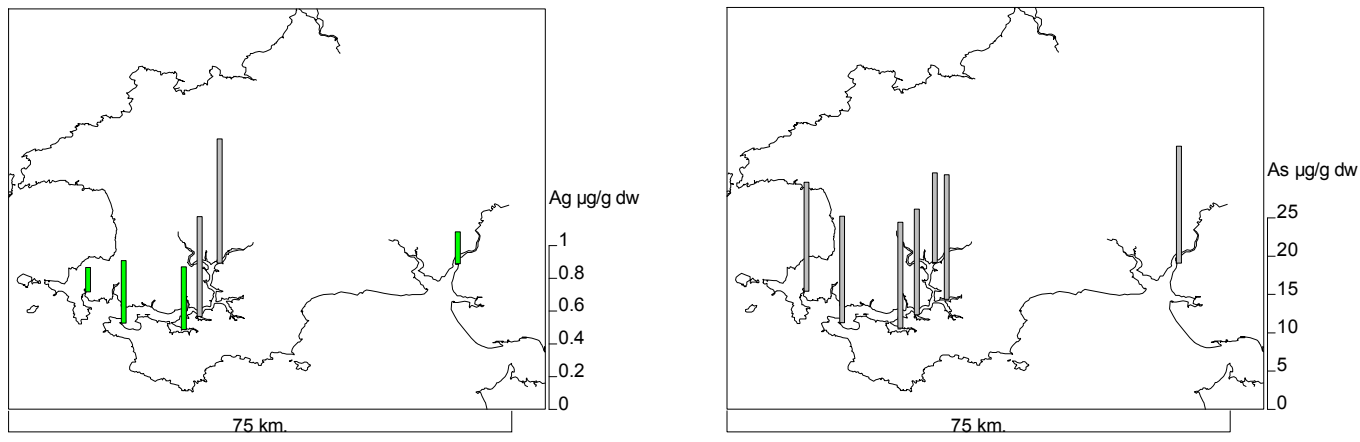

CdNereis
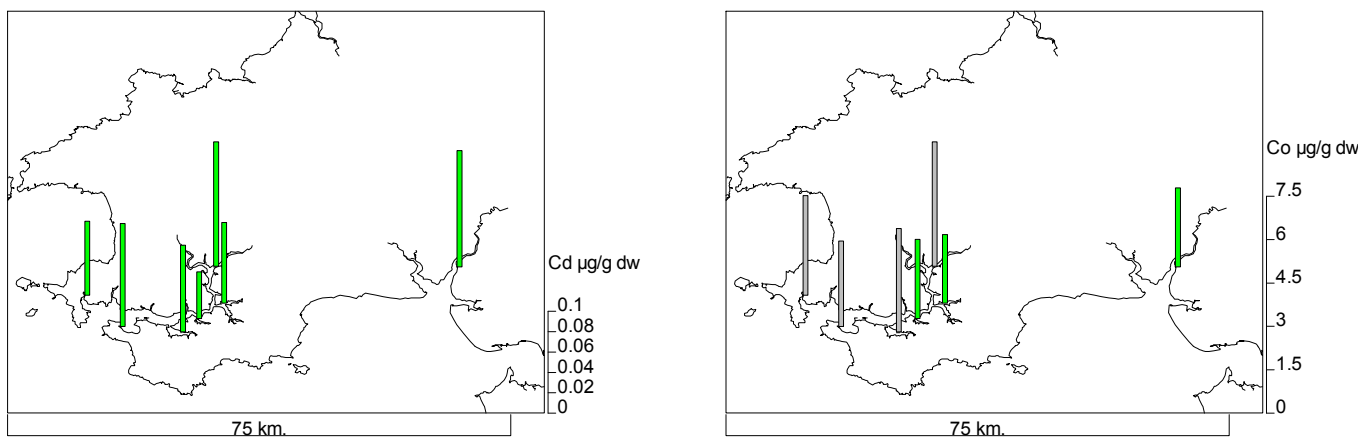

CrNereis

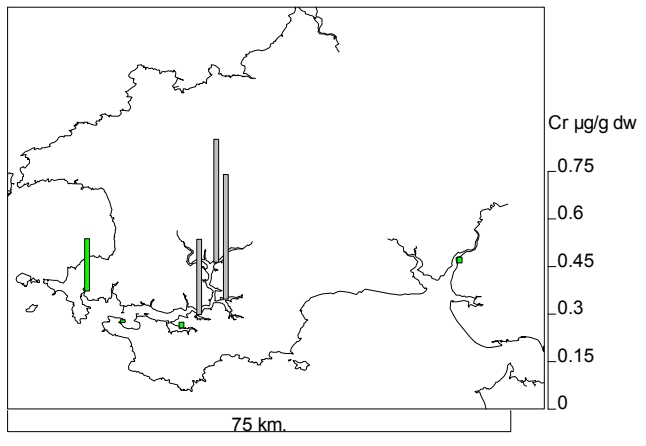

Cu Nereis

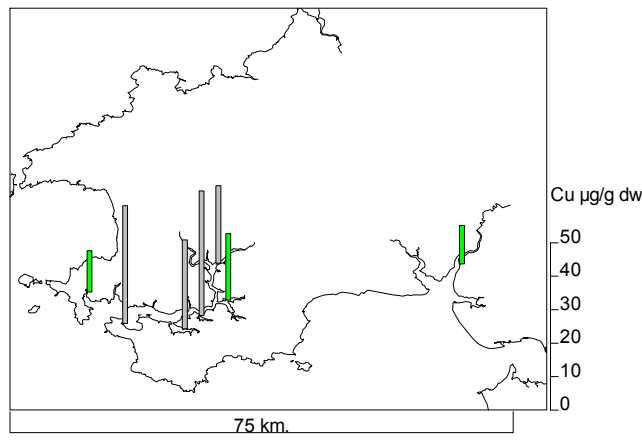

$\mathrm{Hg}$ Nereis
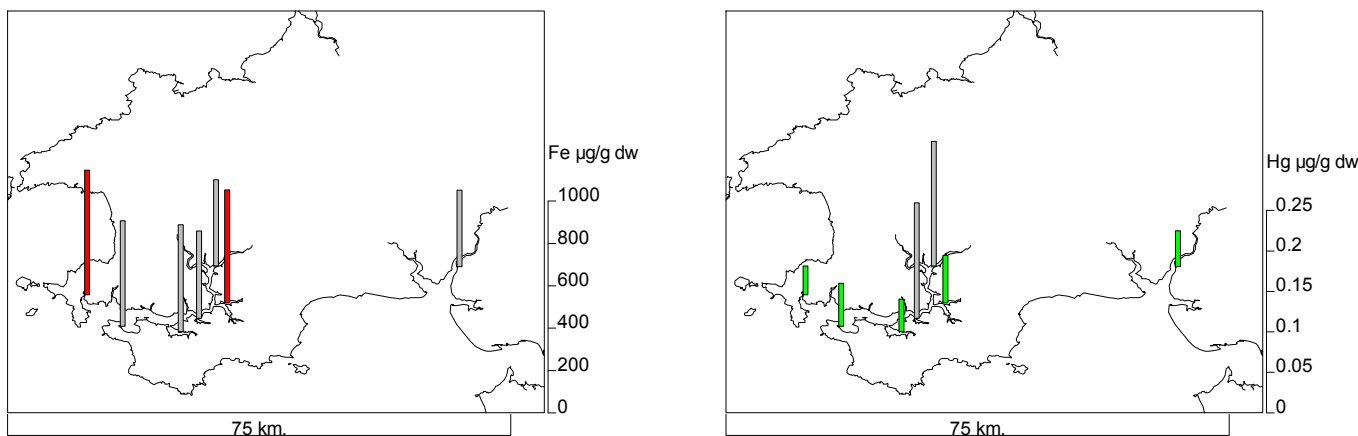

Figure B. Metals in ragworm Nereis diversicolor, $\mu \mathrm{g} \mathrm{g}^{-1} \mathrm{dw}$. Values below the lower quartile value (lowest 25\%) of values in MBA UK data base are plotted as green bars and red if above the upper quartile (highest 25\%). Values in the mid range $\left(25-75^{\text {th }}\right.$ percentile) are represented as grey bars. (cont.)..... 

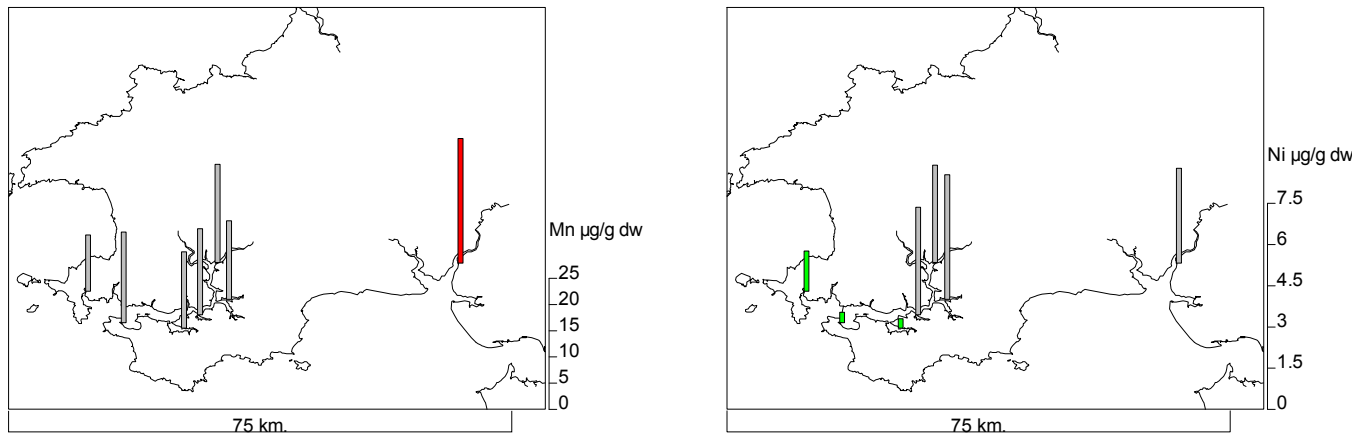

$\mathrm{Pb}$ Nereis

Se Nereis
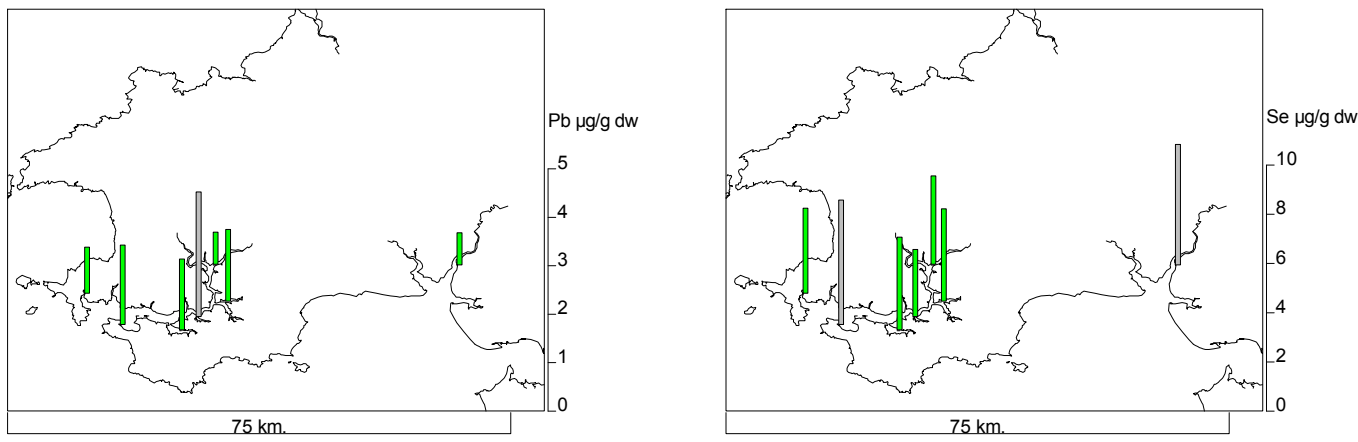

Sn Nereis

Zn Nereis
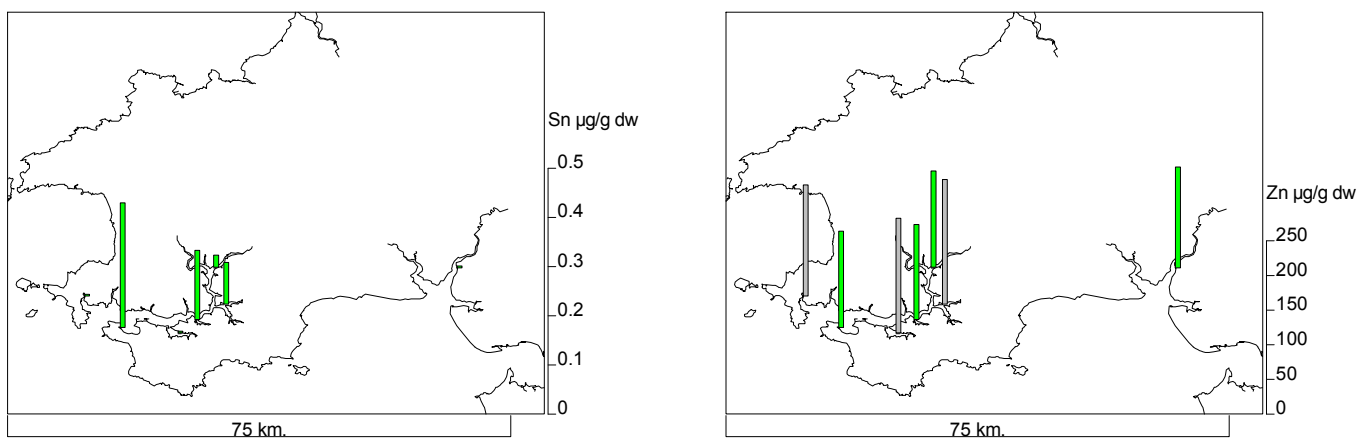

....Figure B (cont.). Metals in ragworm Nereis diversicolor, $\mu^{\prime} \mathrm{g}^{-1} \mathrm{dw}$. Values below the lower quartile value (lowest $25 \%$ ) of values in MBA UK data base are plotted as green bars and red if above the upper quartile (highest $25 \%)$. Values in the mid range $\left(25-75^{\text {th }}\right.$ percentile) are represented as grey bars. 


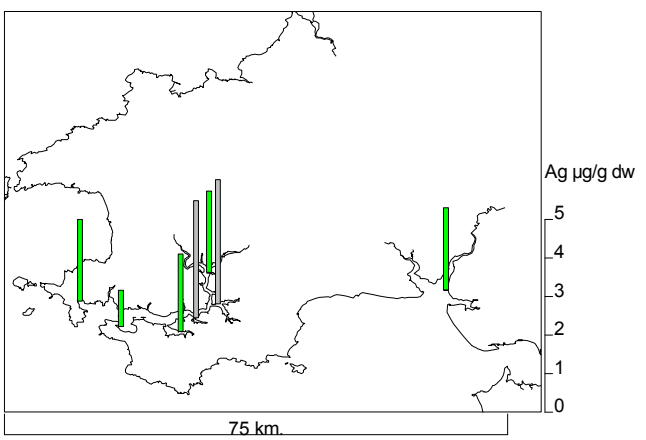

Cd Littorina

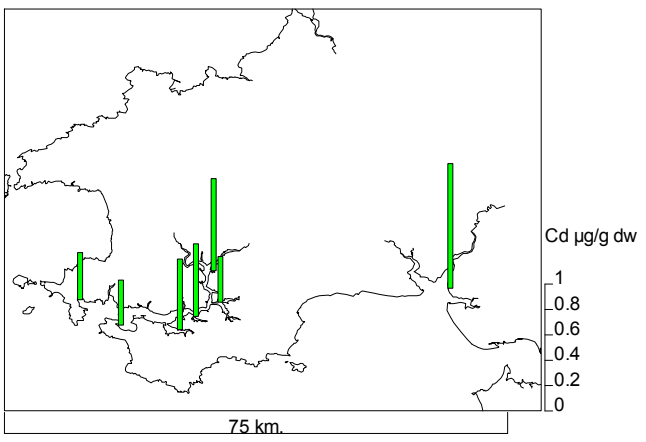

Cr Littorina

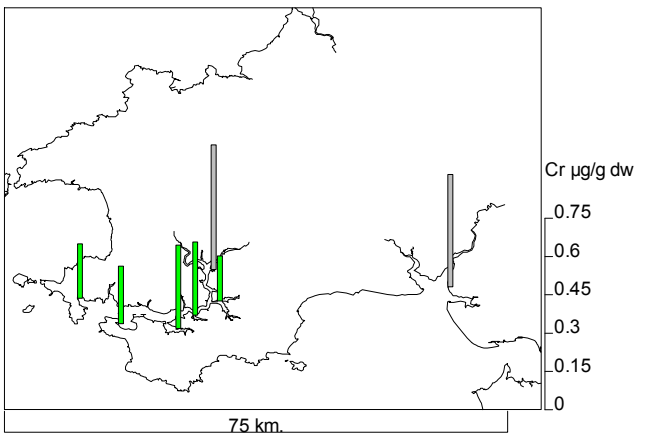

Fe Littorina

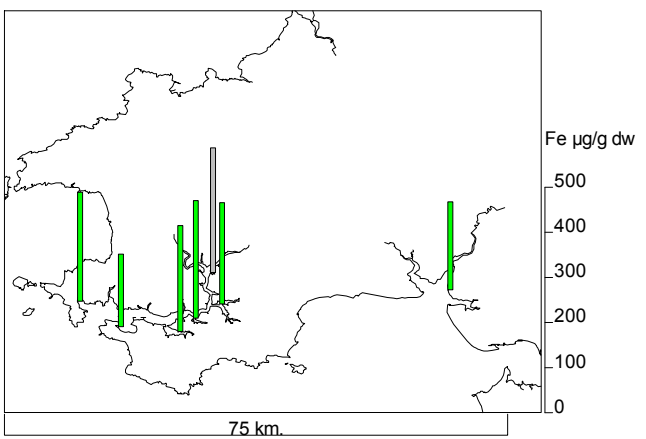

As Littorina

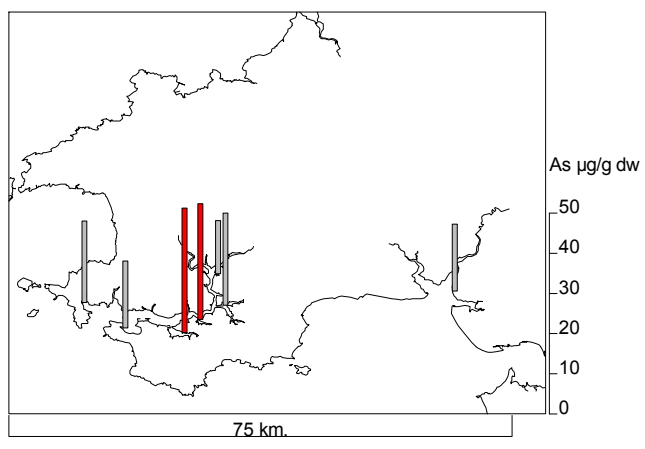

Co Littorina

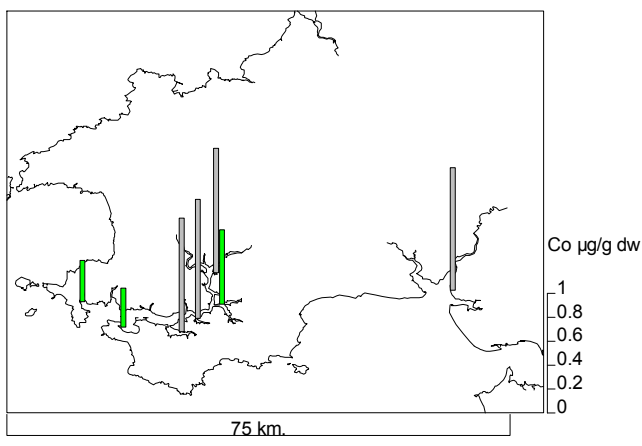

Cu Littorina

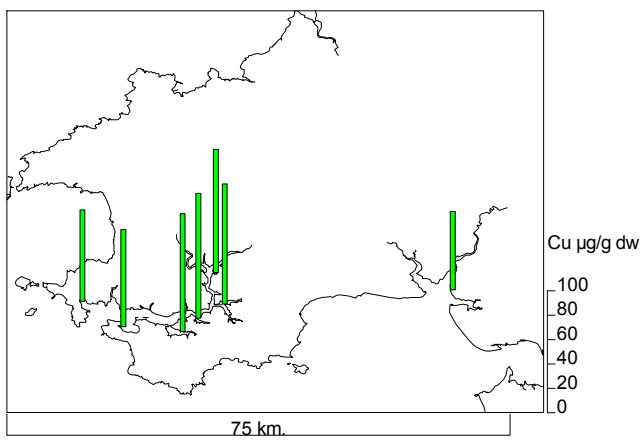

Hg Littorina

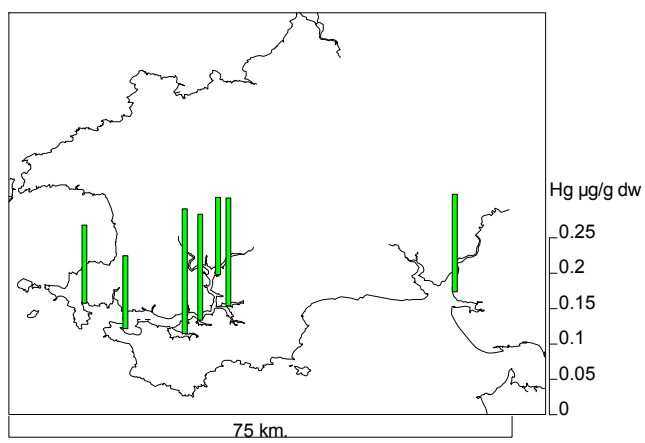

Figure C. Metals in winkles Littorina littorea, $\mu \mathrm{g} \mathrm{g}^{-1} \mathrm{dw}$. Values below the lower quartile value (lowest 25\%) of values in MBA UK data base are plotted as green bars and red if above the upper quartile (highest $25 \%$ ). Values in the mid range $\left(25-75^{\text {th }}\right.$ percentile) are represented as grey bars. (cont)..... 

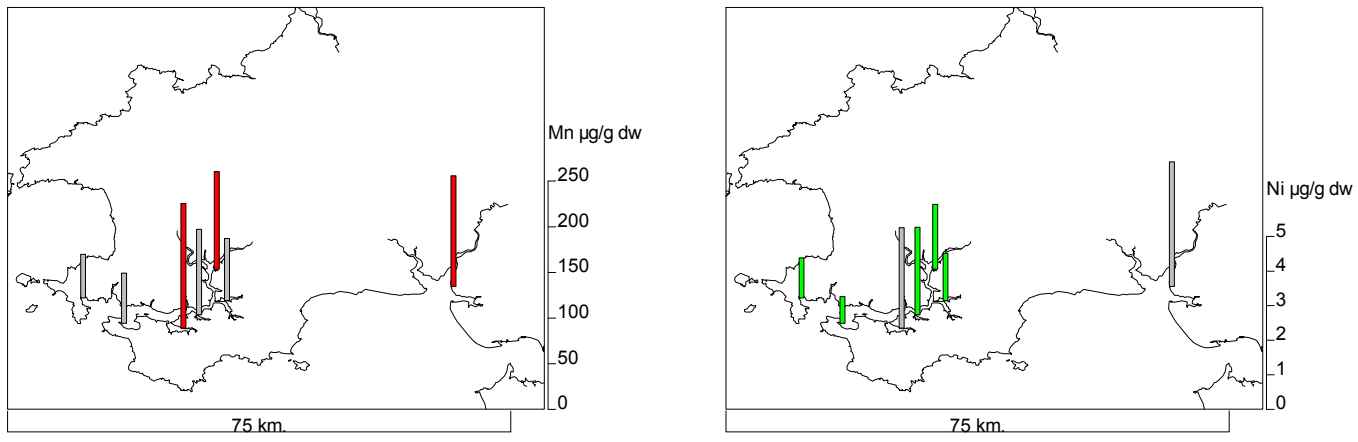

$\mathrm{Pb}$ Littorina

Se Littorina
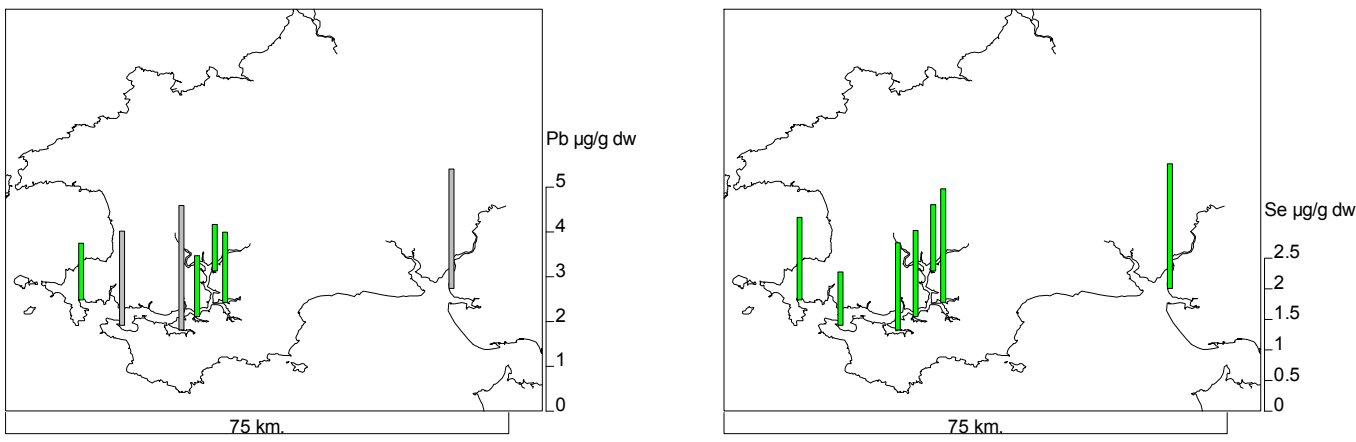

Sn Littorina

Zn Littorina
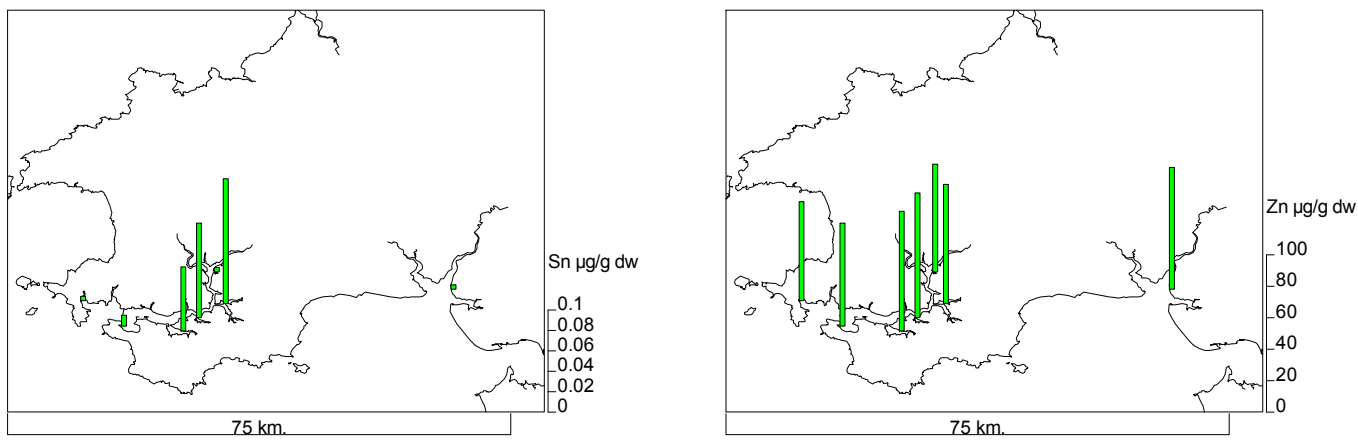

...Figure C (cont.). Metals in winkles Littorina littorea, $\mu \mathrm{g} \mathrm{g}^{-1} \mathrm{dw}$. Values below the lower quartile value (lowest 25\%) of values in MBA UK data base are plotted as green bars and red if above the upper quartile (highest $25 \%)$. Values in the mid range $\left(25-75^{\text {th }}\right.$ percentile) are represented as grey bars. 

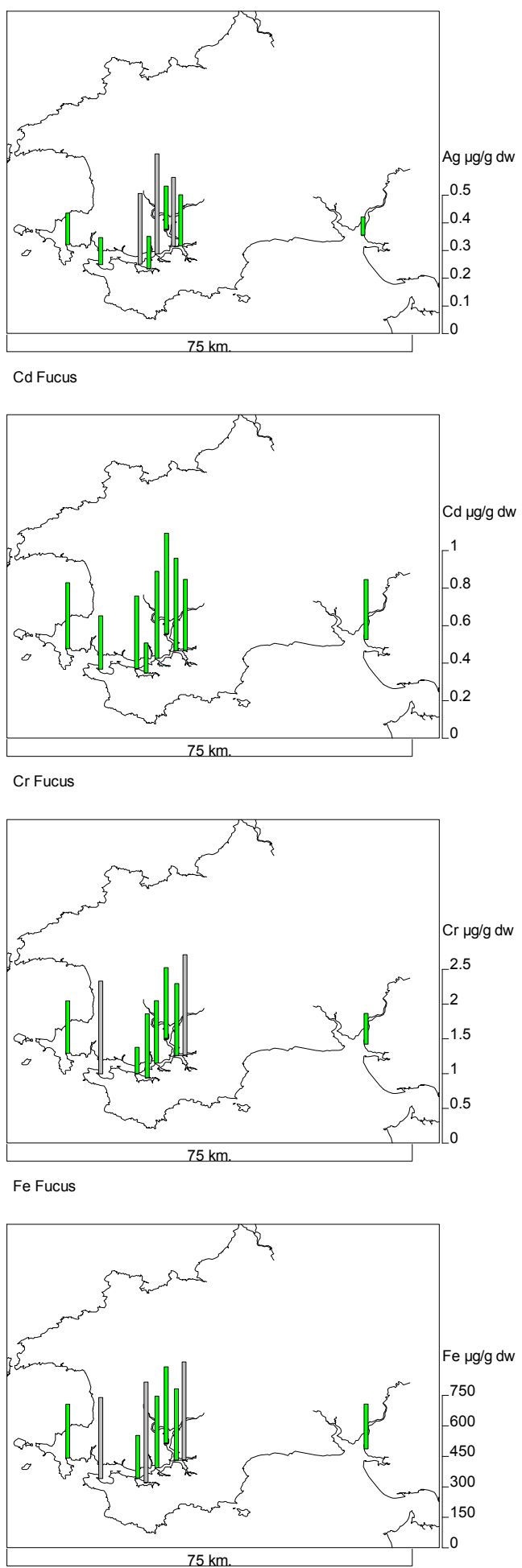

As Fucus

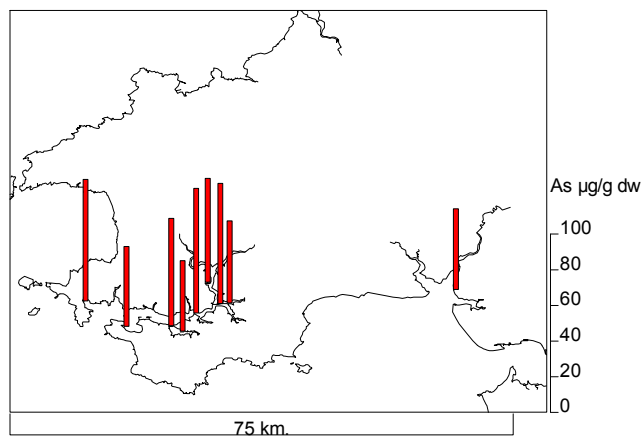

Co Fucus

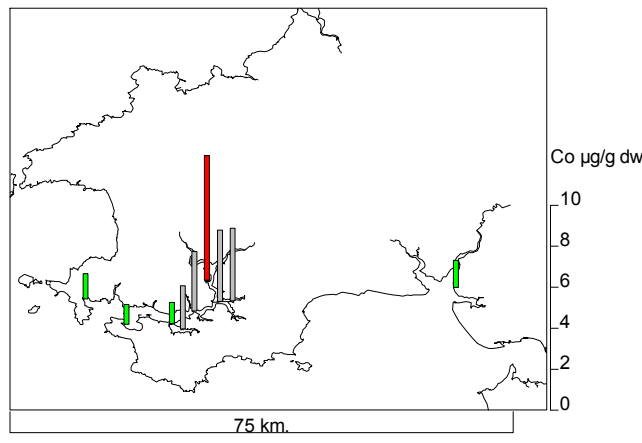

Cu Fucus

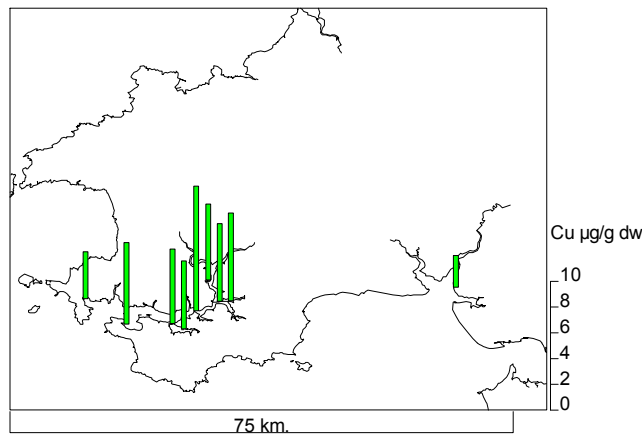

Hg Fucus

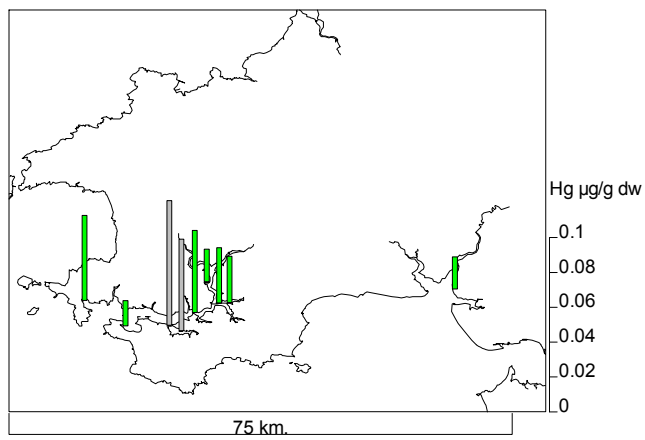

Figure D. Metals in seaweed Fucus vesiculosus, $\mu \mathrm{g}^{-1} \mathrm{dw}$. Values below the lower quartile value (lowest 25\%) of values in MBA UK data base are plotted as green bars and red if above the upper quartile (highest $25 \%$ ). Values in the mid range $\left(25-75^{\text {th }}\right.$ percentile) are represented as grey bars. (cont.)..... 

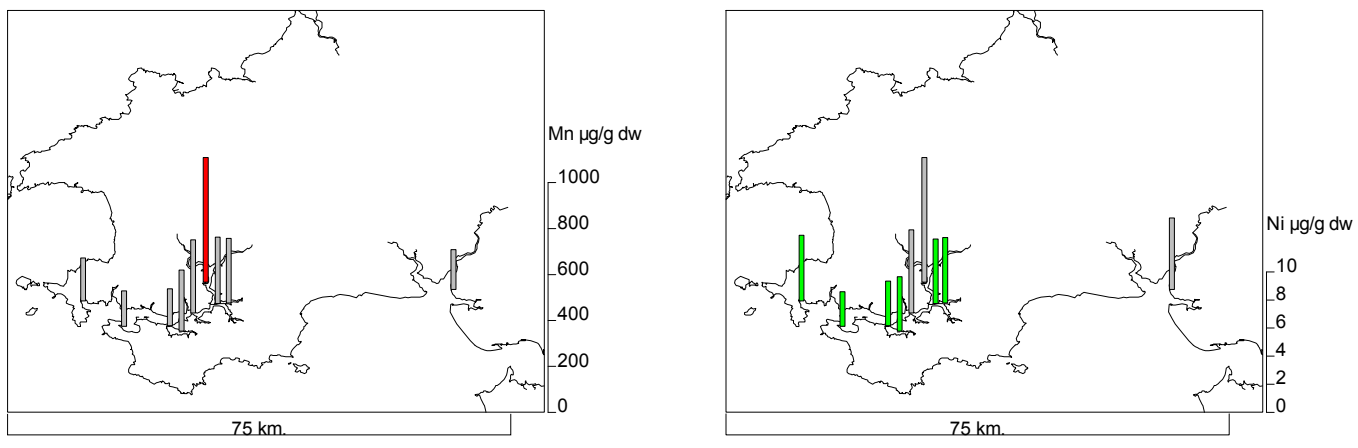

$\mathrm{Pb}$ Fucus
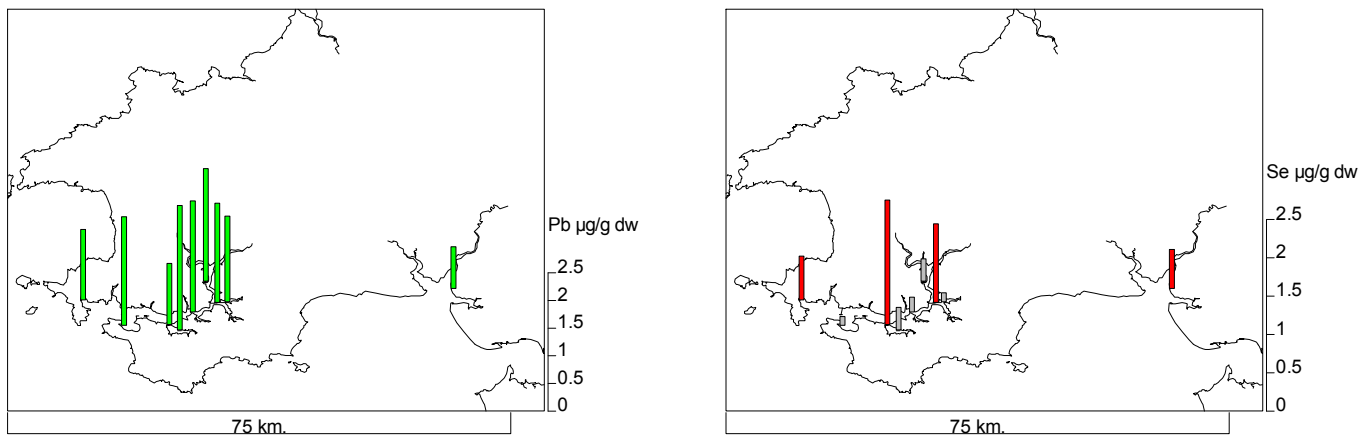

Sn Fucus
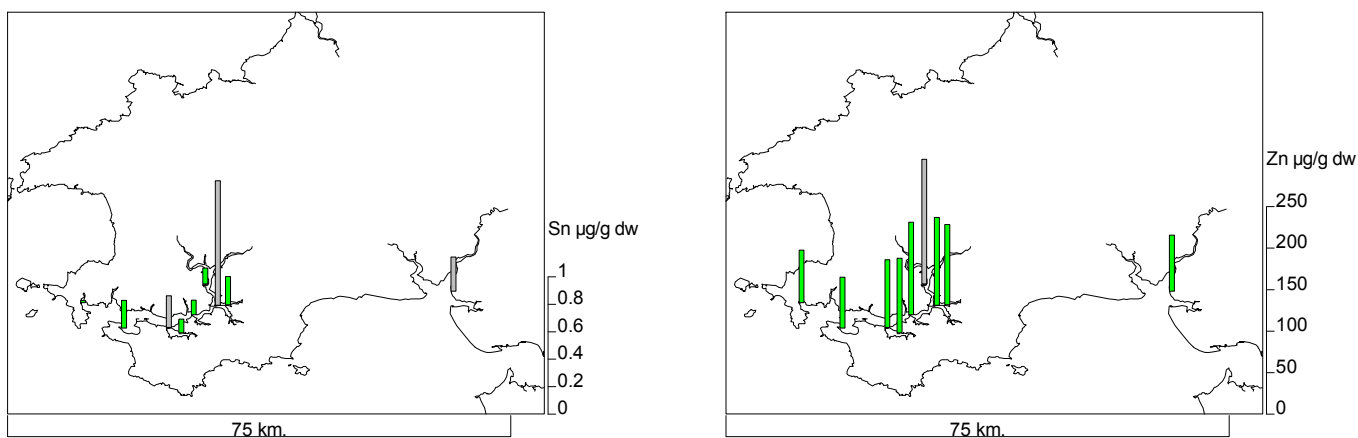

...Figure D (cont.). Metals in seaweed Fucus vesiculosus, $\mu \mathrm{g}^{-1} \mathrm{dw}$. Values below the lower quartile value (lowest $25 \%$ ) of values in MBA UK data base are plotted as green bars and red if above the upper quartile (highest $25 \%)$. Values in the mid range $\left(25-75^{\text {th }}\right.$ percentile) are represented as grey bars.
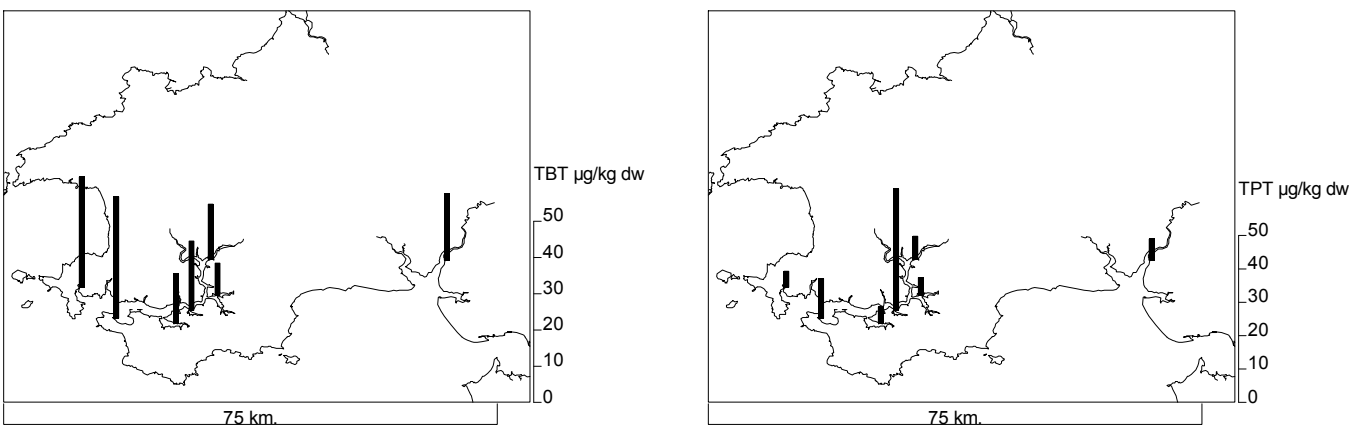

Figure E. TBT and TPT concentrations ( $\mu \mathrm{g} \mathrm{kg-1} \mathrm{dw}$ ) in ragworm Nereis diversicolor 
Table A Background Concentrations (BC) and Background Assessment Criteria (BAC) for PAHs in mussels (2004/5 data; OSPAR, 2007)

( $\mu \mathrm{g} \mathrm{kg}^{-1}$ dry weight)

\begin{tabular}{lcc}
\hline & BC & BAC \\
\hline Naphthalene & 1 & 81.2 \\
Phenanthrene & 4.5 & 12.6 \\
Anthracene & 1 & 2.7 \\
Fluoranthene & 7 & 11.2 \\
Pyrene & 5.5 & 10.1 \\
Benz[a]anthracene & 1.5 & 3.6 \\
Chrysene & 6.5 & 21.8 \\
Benzo[a]pyrene & 1 & 2.1 \\
Benzo[ghi]perylene & 2.5 & 7.2 \\
Indeno[123-cd]pyrene & 2 & 5.5 \\
& & \\
\hline
\end{tabular}


Table B. Organotins ( $\mu \mathrm{g} \mathrm{kg}^{-1}$ ) in Nereis diversicolor, September 2007 and Mytilus edulis, March 2008.

\begin{tabular}{|c|c|c|c|c|c|c|c|c|c|}
\hline \multicolumn{10}{|c|}{ Organotins $\mu \mathrm{g} \mathrm{kg}^{-1}$ (dry weight) } \\
\hline Site & Map Ref. & Mouth & Date & MBT & DBT & TBT & MPT & DPT & TPT \\
\hline \multicolumn{10}{|c|}{ Nereis diversicolor } \\
\hline Tywi ${ }^{\mathbf{a}}$ & SN370117 & & $11 / 09 / 2007$ & 64.03 & 12.22 & 18.48 & 28.72 & 31.53 & 6.47 \\
\hline Dale $^{\mathbf{a}}$ & SM815075 & 6.5 & $13 / 09 / 2007$ & 41.76 & 15.84 & 30.72 & 35.81 & 24.02 & 5.02 \\
\hline Angle $^{\mathbf{a}}$ & SM868028 & 7.4 & $12 / 09 / 2007$ & 166.26 & 104.77 & 33.72 & 44.58 & 30.93 & 12.04 \\
\hline Pennar & \begin{tabular}{|l|} 
SM959020 \\
\end{tabular} & 16.8 & $12 / 09 / 2007$ & 42.20 & 15.73 & 13.85 & 37.86 & 13.38 & 5.13 \\
\hline Pembroke Ferry (Waterloo) & SM982040 & 19.0 & $12 / 09 / 2007$ & 88.91 & 35.41 & 19.24 & 163.65 & 115.60 & 36.58 \\
\hline Lawrenny ${ }^{\mathrm{b}}$ & SN017063 & 21.8 & $13 / 09 / 2007$ & 60.15 & 31.28 & 9.04 & 38.54 & 19.51 & 5.51 \\
\hline Landshipping & \begin{tabular}{|l|} 
SN011118 \\
\end{tabular} & 28.0 & $13 / 09 / 2007$ & 68.12 & 39.85 & 15.41 & 48.73 & 180.69 & 7.14 \\
\hline \multicolumn{10}{|c|}{ Mytilus edulis } \\
\hline Tywib & \begin{tabular}{|l|l|} 
SN361082 \\
\end{tabular} & - & $09 / 03 / 2008$ & 54 & 2 & $<1$ & $<1$ & 0.66 & 0.27 \\
\hline Daleb & \begin{tabular}{|l} 
SM809065 \\
\end{tabular} & 5.5 & $11 / 03 / 2008$ & 454 & 14 & 62 & $<1$ & $<1$ & 1.26 \\
\hline Angle $^{b}$ & \begin{tabular}{|l|} 
SM870027 \\
\end{tabular} & 7.3 & $10 / 03 / 2008$ & 79 & 13 & 59 & $<1$ & 0.9 & 1.71 \\
\hline Pennar Mouth & SM943028 & 13.8 & $10 / 03 / 2008$ & 106 & 15 & 72 & $<1$ & $<1$ & 1.48 \\
\hline Pennar & SM959020 & 16.8 & $10 / 03 / 2008$ & 82 & 13 & 78 & $\leq 1$ & 0.93 & 2.64 \\
\hline Pembroke Ferry (Ferry Inn) & SM974047 & 17.0 & $10 / 03 / 2008$ & 104 & 34 & 123 & $<1$ & $<1$ & 1.49 \\
\hline Ferry Hill & SN003061 & 21.0 & $11 / 03 / 2008$ & 104 & 19 & 103 & $<1$ & 0.83 & 3.07 \\
\hline Lawrenny $^{\text {a }}$ & \begin{tabular}{|l} 
SN009062 \\
\end{tabular} & 21.0 & $11 / 03 / 2008$ & 336 & 29 & 100 & $<1$ & 0.73 & 2.73 \\
\hline Black Tar & \begin{tabular}{|l} 
SM999093 \\
\end{tabular} & 24.8 & $11 / 03 / 2008$ & 129 & 17 & 83 & $<1$ & $\leq 1$ & 2.95 \\
\hline & & & & & & & & & \\
\hline
\end{tabular}

$<$ in tables denote values below Limit of Detection.

a,b 'Soft substrate' sites may be slightly different from 'rocky shore habitats' : see Appendix 1 for site details 
Table C PCBs ( $\mu \mathrm{g} \mathrm{kg}^{-1}$ ) in Nereis diversicolor, September 2007 and Mytilus edulis, March 2008.

\begin{tabular}{|c|c|c|c|c|c|c|c|c|c|c|c|}
\hline Site & Map Ref. & Mouth & Date & $\begin{array}{l}\text { PCB } \\
028\end{array}$ & $\begin{array}{l}\text { PCB } \\
052\end{array}$ & $\begin{array}{l}\text { PCB } \\
101\end{array}$ & $\begin{array}{l}\text { PCB } \\
118\end{array}$ & $\begin{array}{l}\text { PCB } \\
153\end{array}$ & $\begin{array}{l}\text { PCB } \\
138\end{array}$ & $\begin{array}{l}\text { PCB } \\
180\end{array}$ & $\begin{array}{l}\text { Total of } \\
7 \text { PCBs }\end{array}$ \\
\hline \multicolumn{12}{|c|}{ Nereis diversicolor } \\
\hline Tywi ${ }^{\mathbf{a}}$ & SN370117 & - & $11 / 09 / 2007$ & 1.044 & 1.181 & 0.000 & 0.000 & 3.111 & 1.708 & 0.000 & 7.044 \\
\hline Dale ${ }^{a}$ & SM815075 & 6.5 & $13 / 09 / 2007$ & 2.022 & 0.608 & 0.456 & 0.000 & 2.266 & 1.234 & 0.000 & 6.586 \\
\hline Angle $^{a}$ & SM868028 & 7.4 & $12 / 09 / 2007$ & 2.930 & 0.578 & 0.364 & 0.726 & 3.211 & 1.551 & 1.686 & 11.046 \\
\hline Pennar & SM959020 & 16.8 & $12 / 09 / 2007$ & 3.336 & 0.660 & 0.434 & 0.623 & 1.751 & 0.943 & 0.705 & 8.452 \\
\hline Pembroke Ferry (Waterloo) & SM982040 & 19.0 & $12 / 09 / 2007$ & 2.900 & 0.493 & 0.000 & 0.915 & 3.279 & 1.686 & 0.966 & 10.239 \\
\hline Lawrennyb & SN017063 & 21.8 & $13 / 09 / 2007$ & 2.648 & 0.568 & 0.491 & 0.776 & 2.167 & 1.255 & 0.974 & 8.878 \\
\hline Landshipping & SN011118 & 28.0 & $13 / 09 / 2007$ & 1.579 & 0.816 & 0.000 & 0.625 & 3.662 & 1.601 & 1.253 & 9.535 \\
\hline \multicolumn{12}{|c|}{ Mytilus edulis } \\
\hline Tywib & SN361082 & - & $09 / 03 / 2008$ & 0.272 & 0.558 & 1.250 & 1.330 & 7.406 & 2.841 & 0.030 & 13.688 \\
\hline Daleb $^{b}$ & SM809065 & 5.5 & $11 / 03 / 2008$ & 0.633 & 0.525 & 11.452 & 16.019 & 7.608 & 2.873 & 0.382 & 39.492 \\
\hline Angle $^{b}$ & SM870027 & 7.3 & $10 / 03 / 2008$ & 3.013 & 0.551 & 2.677 & 2.867 & 23.188 & 7.364 & 0.322 & 39.983 \\
\hline Pennar Mouth & SM943028 & 13.8 & $10 / 03 / 2008$ & 0.000 & 0.000 & 2.496 & 2.620 & 10.836 & 4.039 & 0.312 & 20.302 \\
\hline Pennar & SM959020 & 16.8 & $10 / 03 / 2008$ & - & - & - & - & - & - & - & - \\
\hline Pembroke Ferry (Ferry Inn) & SM974047 & 17.0 & $10 / 03 / 2008$ & 0.498 & 0.735 & 2.376 & 2.584 & 11.557 & 3.747 & 0.561 & 22.057 \\
\hline Ferry Hill & SN003061 & 21.0 & $11 / 03 / 2008$ & 0.247 & 0.261 & 1.628 & 1.699 & 7.781 & 2.395 & 0.449 & 14.459 \\
\hline Lawrennya & SN009062 & 21.0 & $11 / 03 / 2008$ & 0.504 & 0.493 & 1.441 & 2.192 & 8.872 & 2.523 & 0.052 & 16.077 \\
\hline Black Tar & SM999093 & 24.8 & $11 / 03 / 2008$ & 0.545 & 0.332 & 1.018 & 1.604 & 4.346 & 1.631 & 0.002 & 9.479 \\
\hline & & & & & & & & & & & \\
\hline & & & & & & & & & & & \\
\hline
\end{tabular}

a,b 'Soft substrate' sites may be slightly different from 'rocky shore habitats' : see Appendix 1 for site details 
Table D. PAHs ( $\mu \mathrm{kg}^{-1}$ ) in Nereis diversicolor, September 2007 and Mytilus edulis, March 2008.

\begin{tabular}{|c|c|c|c|c|c|c|c|c|c|c|c|c|c|c|c|c|c|c|c|}
\hline \multirow[t]{2}{*}{ Site } & \multirow[t]{2}{*}{ Naph. } & \multirow[t]{2}{*}{$\begin{array}{l}\text { 1-Me- } \\
\text { naph. }\end{array}$} & \multirow[t]{2}{*}{-Me naph } & \multirow[t]{2}{*}{ Ace. } & \multicolumn{3}{|c|}{ Fluor. Phen. Anth. } & \multirow[t]{2}{*}{ Fanth. } & \multirow[t]{2}{*}{ Pyr. } & \multirow{2}{*}{\multicolumn{3}{|c|}{ B(a) A Chrys. B(b)F }} & \multirow[t]{2}{*}{ Pery. } & \multicolumn{2}{|c|}{$B(k) F \quad B(a) P$} & \multirow[t]{2}{*}{$\begin{array}{c}\text { DB(ah) } \\
\text { A }\end{array}$} & \multirow[t]{2}{*}{$\begin{array}{c}\text { B(ghi) } \\
\text { P }\end{array}$} & \multirow[t]{2}{*}{$\begin{array}{l}\text { Ind(123 } \\
\text { cd)P }\end{array}$} & \multirow[t]{2}{*}{$\begin{array}{l}\text { Total } \\
\text { PAHs }\end{array}$} \\
\hline & & & & & & s a dev & rssic & & & & & & & & & & & & \\
\hline Tywi ${ }^{\mathbf{a}}$ & 0.97 & 1.26 & $\mathrm{NA}$ & 0.94 & 4.54 & 49.47 & 1.96 & 14.91 & 5.86 & 1.27 & 2.48 & 2.65 & 0.67 & 0.24 & 0.40 & $<0.06$ & 0.61 & $<0.07$ & 88.3 \\
\hline Dale $^{\mathbf{a}}$ & 3.51 & 1.91 & NA & 2.07 & 4.22 & 55.02 & 3.23 & 65.09 & 66.82 & 3.72 & 4.33 & 5.47 & $<0.22$ & 0.67 & 1.48 & $<0.18$ & 0.33 & $<0.12$ & 218.4 \\
\hline Angle $^{\mathbf{a}}$ & 5.04 & 2.19 & NA & 0.88 & 4.64 & 45.39 & 2.10 & 11.72 & 7.20 & 1.97 & 2.66 & 4.12 & $<0.25$ & 0.19 & 0.76 & $<0.75$ & 1.80 & $<0.13$ & 91.8 \\
\hline Pennar & 2.95 & $<0.99$ & NA & 0.51 & 3.51 & 39.79 & 2.18 & 8.12 & 3.89 & 1.20 & 1.46 & 1.39 & $<0.05$ & $<0.33$ & 0.53 & $<0.06$ & 0.37 & $<0.13$ & 67.4 \\
\hline Pembroke Ferry (Waterloo) & 11.65 & 2.21 & $\mathrm{NA}$ & $<0.30$ & 3.92 & 35.71 & 1.48 & 10.20 & 4.58 & 1.62 & 1.62 & 2.61 & $<0.16$ & $<0.03$ & 0.65 & $<0.29$ & 1.12 & $<0.15$ & 78.3 \\
\hline Lawrenny ${ }^{b}$ & 7.09 & 4.62 & $\mathrm{NA}$ & $<0.14$ & 3.74 & 35.21 & 1.40 & 16.65 & 15.08 & \begin{tabular}{|l|}
1.19 \\
\end{tabular} & 1.96 & 3.62 & $<0.05$ & 1.58 & 1.60 & $<0.06$ & 0.85 & $<0.03$ & 94.6 \\
\hline Landshipping & 3.35 & 2.00 & NA & \begin{tabular}{|l|}
0.78 \\
\end{tabular} & 4.26 & 39.94 & \begin{tabular}{|l|}
2.07 \\
\end{tabular} & 10.16 & \begin{tabular}{|l|}
5.97 \\
\end{tabular} & \begin{tabular}{|l|}
1.31 \\
\end{tabular} & 1.41 & 2.15 & $<0.05$ & $<0.01$ & \begin{tabular}{|l|}
0.29 \\
\end{tabular} & $<0.06$ & 0.30 & $<0.06$ & 74.2 \\
\hline \multicolumn{20}{|c|}{ Mytilus edulis (March 2008) } \\
\hline Tywi ${ }^{\mathbf{b}}$ & \begin{tabular}{|l|}
4.26 \\
\end{tabular} & $\leq 0.77$ & 0.86 & $\leq 0.40$ & 2.00 & 20.6 & $\leq 0.00$ & 25.4 & \begin{tabular}{|l|}
24.1 \\
\end{tabular} & \begin{tabular}{|l|}
2.80 \\
\end{tabular} & 5.23 & 9.13 & \begin{tabular}{|l|}
4.39 \\
\end{tabular} & 3.08 & 1.00 & $\leq 0.00$ & 5.29 & 1.01 & 110.4 \\
\hline Dale $^{\mathbf{b}}$ & 7.10 & 0.92 & 2.10 & $\leq 0.40$ & 1.39 & \begin{tabular}{|l|}
16.3 \\
\end{tabular} & 0.70 & 16.1 & 19.6 & 9.92 & 12.6 & 17.1 & 6.26 & 4.70 & 1.89 & $\leq 0.00$ & 7.92 & 2.57 & 127.7 \\
\hline Angle ${ }^{b}$ & \begin{tabular}{|l|}
3.62 \\
\end{tabular} & 1.86 & 1.63 & $<0.25$ & 2.15 & \begin{tabular}{|l|}
23.1 \\
\end{tabular} & 1.09 & 27.9 & 33.6 & \begin{tabular}{|l|}
12.5 \\
\end{tabular} & 26.8 & 34.2 & 12.0 & 8.08 & \begin{tabular}{|l|}
3.74 \\
\end{tabular} & $\leq 0.03$ & 13.5 & 3.80 & 209.8 \\
\hline Pennar Mouth & \begin{tabular}{|l|}
6.34 \\
\end{tabular} & 3.22 & 2.62 & \begin{tabular}{|l|}
0.84 \\
\end{tabular} & 1.44 & \begin{tabular}{|l|}
18.1 \\
\end{tabular} & 0.31 & 23.8 & \begin{tabular}{|l|}
38.8 \\
\end{tabular} & \begin{tabular}{|l|}
25.5 \\
\end{tabular} & 29.9 & 43.3 & 14.3 & 11.4 & \begin{tabular}{|l|}
5.59 \\
\end{tabular} & $\leq 0.02$ & 14.2 & 4.30 & 244.0 \\
\hline Pennar & \begin{tabular}{|l|l|}
4.74 \\
\end{tabular} & 2.89 & 1.83 & $\leq 0.35$ & 1.35 & 15.5 & \begin{tabular}{|l|}
0.79 \\
\end{tabular} & 16.9 & 23.1 & \begin{tabular}{|l|}
17.8 \\
\end{tabular} & 12.6 & 25.0 & 12.8 & 7.01 & 3.28 & $\leq 0.08$ & 11.4 & 1.93 & 159.3 \\
\hline Pembroke Ferry (Ferry Inn) & 4.13 & 9.29 & 2.01 & 0.62 & 1.75 & 19.8 & 1.02 & 29.2 & 33.5 & 30.7 & 27.4 & 44.2 & 16.2 & 12.2 & 9.58 & 1.55 & 17.6 & 1.59 & 262.3 \\
\hline Ferry Hill & 7.54 & 2.52 & 2.27 & 0.52 & 1.80 & 17.7 & 0.92 & 14.5 & 25.2 & 20.4 & 11.3 & 28.8 & 11.7 & 8.46 & 6.30 & $\leq 0.82$ & 12.7 & 4.66 & 178.1 \\
\hline Lawrenny $^{a}$ & \begin{tabular}{|l|}
3.84 \\
\end{tabular} & 1.28 & 1.59 & \begin{tabular}{|l|l|}
0.68 \\
\end{tabular} & 1.54 & 13.4 & \begin{tabular}{|l|l|}
1.21 & 1 \\
\end{tabular} & 17.5 & 24.6 & 7.55 & 11.2 & 29.2 & 14.2 & 8.22 & 5.92 & 1.25 & 15.4 & 3.70 & 162.3 \\
\hline Black Tar & 5.46 & 2.85 & 1.74 & $\leq 0.15$ & 1.32 & 11.2 & 0.70 & 10.4 & 14.5 & 6.62 & 6.32 & 28.7 & 13.6 & 9.15 & 6.54 & $\leq 0.92$ & 16.9 & 3.45 & 140.7 \\
\hline & & & & & & & & & & & & & & & & & & & \\
\hline & & & & & & & & & & & & & & & & & & & \\
\hline
\end{tabular}

$<$ in tables denote values below Limit of Detection. NA not analysed

a,b 'Soft substrate' sites ${ }^{\mathrm{a}}$ for Nereis may be slightly different from rocky shore habitats ${ }^{\mathrm{b}}$ for Mytilus : 